\title{
Crisis Económica, Cooperativismo e Innovación
}

\author{
Javier Divar Garteizaurrecoa \\ Universidad de Deusto
}

Sumario: La innovación en general, - La innovación en las Cooperativas, - La innovación jurídica cooperativista,- La innovación registral de las Cooperativas, - Las Cooperativas ante la crisis económica,-Anexo.

Resumen: La innovación como causa básica de la constante renovación de la empresa, motivando su permanencia en el mercado, está en la misma filosofía participativa de las cooperativas. El régimen jurídico de las cooperativas ha promovido algunas de las instituciones más novedosas del Derecho de Sociedades. En esa línea es necesario avanzar hacia la unidad registral y publicitaria mercantil.

Palabras clave: innovación, cooperativas, derecho, registro, crisis.

Abstract: As the basic cause of constant renovation in firms and the motivating factor for their permanence on the market, innovation is found within the cooperative participative philosophy itself. The legal system of cooperatives has fostered some of the newest institutions of Company Law. It is necessary to advance along these lines to reach unified registry and mercantile publicity.

Key words: innovation, cooperative, law, registry, crisis. 


\section{La innovación en general}

La renovación es la vida para cualquier instituto social. Ya lo sostiene el viejo dicho popular: "renovarse o morir». Aunque se alcance el éxito, aunque una organización llegue a la excelencia, si no se renueva decae, languidece y termina muriendo. Como suele decirse, «también se muere de éxito», por adormecerse en la propia inercia funcional, aun de lo que funciona bien.

Es así un tema vital para las instituciones su renovación constante. Es la esencia del progreso. Como ya indicó don Miguel de Unamuno, «el progreso consiste en renovarse», sin ello toda organización, económica o no, termina apolillándose en su propio conservadurismo. Por bueno que sea un producto, tiene fecha de caducidad.

Si una organización, empresarial o no, no está abierta a su renovación constante, no se abre al progreso, al aire fresco de las nuevas ideas, pierde flexibilidad. Como el deportista que no se somete a las duras disciplinas del entrenamiento. Si no hay renovación, rejuvenecimiento continuo, "nos volvemos inflexibles», como decía Johan W. Goethe. Las instituciones enferman de arterioesclerosis, que afecta a sus elementos estructurales.

Carlos Martínez Alonso, Secretario de Estado del Gobierno de España para la Ciencia y la Investigación, recordaba en un diario («El País», del 9 de septiembre de 2008), al «padre» de la Física Cuántica, Max Planck, que sostenía el carácter fatal de las innovaciones porque sus oponentes «se van muriendo», y después llegan los jóvenes innovadores.

Y como la Empresa es un instituto vivo, por ser una organización económica en funcionamiento, por definición, para vivir ha de renovarse constantemente, como un ser vivo sus células.

El mismo término «innovación» es utilizado desde finales del siglo XIX para referirse económicamente a la renovación. Carlos Martínez Alonso, en el artículo antes citado, se refiere a su utilización por primera vez en ese contexto en 1899, en un informe anónimo en el se hace mención «al carácter refractario del agricultor español a toda innovación hija de los modernos estudios de agronomía», con lo que se explicaba el retraso de entonces del campo español.

La innovación la podemos definir como el proceso por el que una idea o invención desarrolla una utilidad económica. Se trata de una aplicación inventiva a la organización de la empresa.

No es tanto como un procedimiento productivo (patente), que requiere complejos y costosos equipos de investigación tecnológica, sino sencillamente la aplicación de ideas novedosas a las empresas. Aunque se la cite como elemento menor frente a la investigación (I+D+i), como 
ésta puede salvar a la empresa. Además su importancia reside en que sirve a TODAS las empresas.

Requiere, sin embargo, que cada empresa se organice para incorporar las ideas de mejora que pueden aportar todos sus miembros y gestione su aplicación práctica. Así sus fuentes de origen se componen por la Creatividad (ideas innovadoras) y la Oportunidad (su aprovechamiento práctico).

\section{La innovación en las Cooperativas}

La propia cultura participativa de las Sociedades Cooperativas facilita su permanente creatividad, al establecerse como derecho propio las intervenciones personales de sus socios-trabajadores.

Es suficiente observar el régimen jurídico cooperativo para verlo: voto directo, acceso electivo a todos los cargos, administración participativa, derecho de los socios a recurrir internamente las sanciones, etc.

A diferencia de las sociedades capitalistas, en las que trabajo y capital conforman comunidades disociadas, por lo que el aprovechamiento de las ideas innovadoras del personal requieren estructuras específicas, de las que los empleados suelen recelar, en las Cooperativas la opinión del trabajador-socio es un derecho societario.

Sólo es necesario encauzar su utilización, es decir, imponer que la Dirección articule mecanismos de aplicación de las ideas innovadoras al proceso productivo y organizativo.

Numerosas pequeñas Cooperativas han mejorado la presentación de sus productos, sus diseños, los establecimientos, la atención al cliente, etc., con las ideas aportadas por sus propios socios, los primeros interesados en el éxito de su propia sociedad.

Además, la tradición federalista de las Cooperativas facilita la creación de sus corporaciones societarias, uniones cuyas consecuencias prácticas pueden ir desde humildes aportaciones a la innovación a las «alianzas tecnológicas». Como reciente ejemplo de éstas últimas puede destacarse el novedoso "Polo de Innovación Garaia», de Mondragón, en el que la colaboración con las instituciones públicas facilita que «interactúen los tres elementos implicados de lleno en el mundo de la innovación: las empresas, el ámbito universitario y los centros tecnológicos», como resume el editorial de la revista «Trabajo y Unión» (T.U. Lankide, Mondragón, octubre de 2008). Que concluye sosteniendo que si se pretende "cumplir la misión que nos hemos propuesto de generar empleo preferentemente cooperativo, adecuado al desarrollo de nuestro entorno, la innovación es una necesidad perentoria». 
En esta línea de atención a la privilegiada posición de las Cooperativas y la 3/.Economía Social ante las dificultades económicas, el profesor José Félix Tezános, en la revista Cuadernos de la Economía Social ( $\left.N^{\circ} .4 / 2008\right)$ dice que «la filosofía de la economía social aporta, precisamente, algunas de las soluciones necesarias ante la actual deriva social y los riesgos de fractura y exclusión social», y concluye :»Las empresas de economía social aspiran a generar empleos de calidad, más seguros y con ingresos razonables, fomentan la conciencia implicativa y las prácticas de corresponsabilidad, permiten - y propician - una productividad equilibrada, facilitando la diseminación de la riqueza y las posibilidades de que los seres humanos concretos tomemos las riendas en un mundo desbocado, recuperando los necesarios equilibrios interpersonales, interterritoriales y medioambientales».

Y en el mismo número citado de la Revista Cuadernos de Economía Social, José Luis Jiménez, Director General de Transformación Empresarial de Innobasque, insiste en "hacer hincapié en el factor de competitividad más importante, las personas y su nivel de conocimiento, desarrollando sus capacidades creativas»; y Andoni García, Director del Polo Tecnológico Garaia, remacha el argumento diciendo textualmente: «La respuesta no es más I+D, sino socializar la innovación y pasar a crear culturas innovadoras».

\section{La innovación jurídica cooperativista}

Las Cooperativas, al aplicar sus características estatutarias, han creado a lo largo de los años (desde mediados del siglo XIX) una cultura económica propia, la llamada Cultura Cooperativa. Para su establecimiento normativo los ordenamientos jurídicos han ido innovando el Derecho de Sociedades con ella, a tal punto que éste ha evolucionado hacia una línea participativa y abierta, conforme al ideario social y democrático, esencia del Cooperativismo.

El Cooperativismo, por ejemplo, introdujo la innovación de los socios estatutarios, junto a los de pleno derecho, para atender a partícipes especiales de las compañías (asociados o socios inactivos, colaboradores, trabajadores, temporales, etc.). Introdujo también en la legislación societaria los fondos sociales obligatorios para su destino asistencial, educacional y comunitario. También aportó el sistema de actualizaciones a capital y el régimen de sociedades de capital variable. Igualmente fue pionero en el tratamiento societario de los consorcios privados o uniones entre sociedades autónomas, los órganos complementarios de carácter estatutario (Comité de Recursos, Consejo Social,...), los derechos indivi- 
duales de información societaria fuera de la corporativa en las Juntas, y una larga serie de innovaciones jurídicas que le han convertido en la rama más avanzada y compleja del Derecho de Sociedades.

En esa misma línea innovadora, ante las dificultades económicas actuales, debemos esperar del Cooperativismo sus aportaciones a la tecnología jurídica en favor de la lucha contra el paro y la pobreza, de puesta en valor de las personas, de incremento de la solidaridad, de ayuda a la cultura y a la educación ante su creciente mercantilización, de apoyo en fin de la Democracia Económica.

En el ámbito jurídico para nosotros más cercano de la Comunidad Autónoma del País Vasco, la vigente Ley de Cooperativas de 24 de junio de 1993, ya se adecuóa las utilidades empresariales del momento en apoyo a la constitución de pequeñas 4/.sociedades, como propició la Carta Feria de la UE, con la reforma de 20 de junio de 2000, reduciendo el número mínimo de socios a sólo tres (dos a posteriori con la última reforma de la Ley) y reduciendo también a la mitad el importe nominal mínimo de capital (igualándolo al de las Sociedades Limitadas). Más tarde la reforma de 1 de diciembre de 2006 fue pionera en aplicar a las Cooperativas en general las normas internacionales de contabilidad conforme determinó el Reglamento UE 1606/2002 del Parlamento Europeo y del Consejo, de 19 de julio de 2002, completado por el Reglamento 1725/2003 de la Comisión Europea, de 29 de septiembre de 2003.

Ya la propia Ley de 1993 había sido pionera en establecer innovaciones cooperativas de utilidad práctica, entre otras, como destacables, la regulación de las llamadas Cooperativas mixtas, para incorporar al capital a socios exclusivamente capitalistas, o el Consejo Social, como órgano de regulación estatutaria de fiscalización de la vida laboral en las Cooperativas, o, finalmente, la regulación de las Corporaciones Cooperativas como figura confederativa de organización, toma de decisiones y signo distintivo corporativo, con personalidad jurídica cooperativa, para articular los grandes grupos societarios del orden propio.

\section{La innovación registral de las Cooperativas}

Por citar un solo caso, el más perentorio, en el Derecho español de Sociedades Cooperativas subsiste aún un viejo y recurrente problema que debe ser tratado normativamente en una «innovación jurídica» muy necesaria del Derecho interno. La que imponga la inscripción de todas las Cooperativas en el Registro Mercantil y su consecuente publicidad en el Boletín Oficial del Registro Mercantil. 
A causa de la historia legislativa cercana (me refiero a la cesión competencial de la materia por la II. ${ }^{a}$ República Española), el Cooperativismo ha perdido "mercantilidad» en el Derecho interno, lo que supone una desventaja comparativa con el resto de Sociedades, máxime ante un mercado abierto como el de la UE, en el que rige el principio de libre circulación, que requiere una información igualitaria entre los sujetos económicos para garantizar la seguridad jurídica mercantilista.

La falta de inscripción en el Registro Mercantil de las Cooperativas es una anormalidad que limita la seguridad jurídica de las mismas y que les excluye de la publicidad mercantilista que el Registro Mercantil otorga. Es además contraria al propio Código de Comercio, cuyo artículo 124 "considera mercantiles y sujetas a sus disposiciones» a las Cooperativas cuyo objeto no sea «mutualístico», como es el caso general de las Cooperativas en la actualidad, lo que supone, conforme al artículo 119 del propio Código, que su escritura constitutiva «se presentará para su inscripción en el Registro Mercantil».

La situación actual es contraria incluso a la propia lógica jurídica, puesto que otros sujetos jurídicos poco «comercialistas», algunos también cedidos competencialmente en los Estatutos de las Comunidades Autónomas, como las Mutualidades de Previsión Social o los Fondos de Pensiones, son de inscripción obligatoria conforme determina el artículo 81 del Reglamento del Registro Mercantil (por cierto un mero Real Decreto, cuya modificación no supondría el fin del mundo).

El caso es incluso contrario a la misma lógica económica. ¿Cómo puede sostenerse que una pequeñísima Sociedad Limitada, pongamos por caso, tenga que inscribirse en el Registro Mercantil y una gran Sociedad Cooperativa, como Eroski o Fagor, por ejemplo, con miles de socios, notabilísima facturación, amplias cuentas de resultados, gran volumen de empleo y reconocidas relaciones internacionales no estén sometidas al Registro Mercantil?.

Ni siquiera el control competencial de las distintas Administraciones sirve de justificación, puesto que en otras formas societarias se impone el doble registro, como es el caso, entre otros, de las Sociedades Laborales o las Sociedades Deportivas o las Cajas de Ahorros o la práctica totalidad de las Ilamadas Sociedades Especiales, sin que ello cause mayores problemas.

El propio Reglamento de la UE (n. ${ }^{\circ}$ 1435/ 2003 del Consejo, de 22 de julio de 2003, relativo al Estatuto de la Sociedad Cooperativa Europea, SCE) por el que se establecen las Sociedades Cooperativas Europeas, dice en materia de su publicidad jurídica, en su artículo 12.1 : «Los documentos y los datos de una SCE a los que deba darse publicidad en virtud del presente Reglamento se harán públicos del modo que estipule 
la legislación en materia de sociedades anónimas del Estado miembro en el que la SCE tiene su domicilio social». Y ello deriva, en lógica jurídica, de que previamente el artículo 11.1 del Reglamento Europeo dice, en materia de registro: "Toda SCE deberá estar registrada en el Estado miembro de su domicilio social, en el registro que señale la legislación de ese Estado miembro de conformidad con la legislación aplicable a las sociedades anónimas».

Nada por tanto impide, ni en la lógica jurídica ni en la económica, ni tampoco es, como vemos, contrario al Derecho comparado ni a la normativa común europea, que las Sociedades Cooperativas en España se inscriban en el Registro Mercantil, con lo que realmente se harán jurídicamente comunes, ganarán en principio de legalidad, y estarán beneficiadas por la publicidad mercantilista general, incluida la derivada del Boletín Oficial del Registro Mercantil.

En la muy citada sentencia del Tribunal Constitucional del 29 de julio de 1983, en relación a la anterior Ley Vasca de Cooperativas de 11 de febrero de 1982, los Antecedentes de la misma hacen referencia a la brillante defensa del Abogado del Estado que en apoyo de su posición cita precisamente el artículo 10.23 del Estatuto del País Vasco, que atribuye a la Comunidad competencia en materia de Cooperativas «conforme a la legislación general de carácter mercantil», de lo que concluye que «el derecho mercantil no es algo diferente del derecho cooperativo». En tal base argumenta que la Ley vasca de Cooperativas «olvida el principio mercantil de la inscripción de todos los que realicen operaciones comerciales, sean comerciantes o no comerciantes, en el Registro Mercantil, y especialmente de todas las sociedades que ejerzan actividades comerciales, tengan o no fin de lucro».

La propia representación del Gobierno Vasco sostenía, y así lo recogen literalmente los citados Antecedentes de la Sentencia del Constitucional, que «las Cooperativas deben cumplir la esencia de las formalidades societarias mercantiles», pues tienen «intentio mercatorum» y «realizan (o pueden realizar) actos jurídicos con terceros». Precisamente al artículo 119 del Código de Comercio inicia diciendo : «Toda compañía de comercio, antes de dar principio a sus operaciones, deberá hacer constar su constitución, pactos y condiciones, en escritura pública que se presentará para su inscripción en el Registro Mercantil».

Ya en sus Fundamentos Jurídicos el Tribunal Constitucional establece (N. ${ }^{\circ}$ 8), que «toda la regulación del Registro Mercantil, que incluye la determinación de los actos que han de tener acceso al mismo, es de carácter mercantil, cualquiera que sea la ley que la contenga y su denominación».Por ello concluye: "Por lo que la Ley de Cooperativas del País Vasco ha de respetar los supuestos en los que la Ley General de 
Cooperativas de 19 de diciembre de 1974, y su Reglamento de 16 de noviembre de 1978, determinan que ciertos actos han de tener acceso al Registro». Citando la Ley General entonces en vigor, pero deduciéndose con toda claridad que cualquiera otra que la sustituya puede imponer obligaciones registrales mercantiles a cualesquiera legislación autonómica cooperativista.

Y todavía añade el Tribunal Constitucional : «De acuerdo con las consideraciones anteriores, debemos afirmar que en los casos que relaciona el mencionado artículo 47.2 [se refiere al Reglamento de la Ley General de Cooperativas anterior],en cuanto afecten a cooperativas incluidas en el ámbito de la competencia territorial de la Comunidad, deberá efectuarse la toma de razón en el Registro Mercantil».

De todo lo expuesto se deduce claramente el camino legislativo a recorrer para imponer la inscripción mercantil de todas las Cooperativas en España, para mantener la necesaria unidad mercantilista y la seguridad jurídica publicitaria de todas las personas jurídicas del derecho económico. Ese camino pasa por una exigencia en dicho sentido impuesta por la Ley General de Cooperativas, siguiendo lo indicado por el Tribunal Constitucional, como hemos visto, y ha de continuar con una ampliación de los sujetos inscribibles del artículo 81 del Reglamento del Registro Mercantil, en adecuación a la nueva exigencia legal.

Las Comunidades Autónomas no verían alteradas sus competencias ni la validez de sus propios Registros de Cooperativas, sólo que éstas irían a doble registro (como ya sucede con varios sujetos de inscripción mercantil obligatoria en la actualidad), con la toma de razón en el Registro Mercantil de su domicilio social de la inscripción constitutiva previa del Registro de Cooperativas competente, autonómico o central, según atribuyó dichas competencias y las propias legales el mismo Tribunal Constitucional.

\section{Las Cooperativas ante la crisis económica}

En situaciones de crisis o de dificultades económicas la propia fórmula jurídica cooperativa es ya una innovación de cara al establecimiento del empleo, ya que está en la misma naturaleza de las cooperativas de trabajo tener éste como su objeto cooperativizado, y además en forma asociada, con lo que se facilita una colectivización del mismo.

La misma práctica lo ha acreditado, como por ejemplo sucedió en el ámbito de la Unión Europea con ocasión de la llamada «crisis del petróleo» de la década de los ochenta del pasado siglo, en la que ante la pérdida masiva de empleos por parte de las empresas ordinarias el sector cooperativo creó empleo. 
Ello llevó a algunos Gobiernos a la constitución de instituciones especializadas para el fomento de este tipo de empresas, como fue el caso del Gobierno de Francia que creó una Secretaría de Estado para la Economía Social, que tuvo una reconocida actividad en ese campo, muy citada por los estudios económicos y jurídicos a nivel internacional.

Las principales razones que avalan esa postura de fomento de las cooperativas de trabajo en épocas de crisis económicas son fundamentalmente las siguientes:

1. ${ }^{\text {a }} \quad$ Las cooperativas suponen jurídicamente participación de todos sus miembros, por lo que resulta que todos se sienten parte del proyecto de la empresa, lo que suma inercias y evita que se produzcan deserciones del mismo, puesto que todos se sienten responsables y obligados con el éxito conjunto.

2. ${ }^{\text {a }} \quad$ Por la misma razón en las cooperativas de trabajo la información fluye entre sus miembros, lo que dificulta que elementos desinformados alteren su dirección estratégica, lo que facilita su gestión y el cumplimiento de los objetivos planificados por los gerentes.

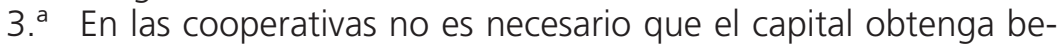
neficios notables y continuados, por la razón de que el objetivo primordial es el mantenimiento del empleo de sus miembros, de forma que esa es la misión de las aportaciones de los socios y no la obtención de lucro.

4. ${ }^{\text {a }} \quad$ En razón a la especial consideración al mantenimiento del empleo en las cooperativas de trabajo pueden acordarse pérdidas puntuales de pagas extras e incluso la reducción de masa salarial ordinaria, lo que en otros tipos societarios suele aparejar graves conflictos sociales.

5. ${ }^{a}$ En las cooperativas de trabajo el excedente económico o beneficio derivado de la cuenta de resultados hay que dedicarlo al objeto social, es decir al trabajo, causa y efecto de los resultados económicos, por lo que lo ordinario en estas sociedades suele ser precisamente la creación de más empleos.

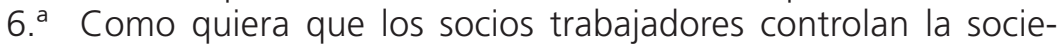
dad, en las cooperativas de trabajo no se producen deslocalizaciones, pues ello es incompatible con el propio interés colectivo de sus partícipes, por lo que las cooperativas suelen estar muy radicadas en el ámbito territorial de su domicilio.

7. ${ }^{\text {a }}$ Por ello mismo las ayudas públicas a estas cooperativas no suelen tener esos problemas e incluso las entidades de crédito tienen la seguridad jurídica de la radicación de estas sociedades. 
8. ${ }^{a} \quad$ En las cooperativas en general y en las de trabajo en particular, la fluidez de la información y de la participación de sus miembros facilita las innovaciones, derivadas del interés colectivo por las mejoras de la producción y la renovación de los productos, lo que es fuente de mejoras para la entidad.

9. ${ }^{a}$ Tanto social como políticamente las cooperativas acreditan por sus virtudes económicas un «interés social», como lo denomina, entre otras, la legislación vasca de sociedades cooperativas, lo que supone un apoyo generalizado a las mismas muy alejado del descrédito público de muchas compañías mercantiles vistas socialmente como meras entidades lucrativistas.

10. ${ }^{\text {a }}$ Por la misma razón las cooperativas son capaces de operar en cualquier régimen político y ante cualquier ambiente económico, lo que las hace resistentes a las alteraciones del medio, como históricamente se ha demostrado incluso ante circunstancias muy adversas, a pesar de las cuales se han mantenido y desarrollado. 
ANEXO: Cuadros estadísticos sobre Investigación, Desarrollo e Innovación, de los Indicadores del Sistema Español de Ciencia y Tecnología 2007.Edición de la Fundación Española para la Ciencia y la Tecnología (FECYT)

\begin{tabular}{|c|c|c|c|c|c|c|c|c|c|c|c|c|}
\hline \multicolumn{13}{|c|}{$\begin{array}{r}\text { I+D EN EL SECTOR ADMINISTRACIÓN } \\
\text { Principales variables }\end{array}$} \\
\hline & 1995 & 1996 & 1997 & 1998 & 1999 & 2000 & 2001 & $20(1)$ & 20003 & 2004 & 2005 & 2006 \\
\hline$N^{*}$ de unidades que realizan $1+D$ & 216 & 199 & 183 & 190 & 182 & 181 & 193 & 239 & 273 & 315 & 357 & 401 \\
\hline De la Administicción del Esiado $(\%)$ & 33.8 & 32,2 & 32,2 & 32,1 & 35,2 & - & 30,0 & 27,6 & 17.2 & 13.7 & 13.7 & 12.5 \\
\hline De las Administrociones cutonómicas y locales (\%) & 66,2 & 67,8 & 67,7 & 67,9 & 64,8 & - & 70,0 & 72,4 & 7,4 & 73,3 & 70,3 & 60,3 \\
\hline Oros contros $1 \%$ & 0 & 0 & 0 & 0 & 0 & - & 0 & 0 & 11.4 & 13,0 & 16,0 & 18,2 \\
\hline Persond empleado en $1+D(E C)$ & 17.152 & 17.865 & 19.189 & 20.170 & 22.283 & 22.399 & 23.467 & 23.211 & 25.760 & 27.166 & 32.077 & 34.588 \\
\hline Investigadores $|\%|$ & 48,8 & 51,0 & 54,7 & 54,6 & 53,5 & 56,7 & 56,8 & 54,4 & $b c, 1$ & 03,1 & 63,7 & 58,0 \\
\hline Oro personal $(\%)$ & - & - & 39,5 & - & 40,5 & - & 44,0 & 45,6 & 39,8 & 30.9 & $3 b, 3$ & 42.0 \\
\hline Mujeres dedicadas a $+D$ (ESC) & - & - & - & - & 9.038 & - & 10.332 & 10.604 & 12.224 & 13.192 & 15.901 & 17.047 \\
\hline Investigodoras $|:|$ & - & - & - & - & - & - & - & - & 58,6 & 617 & 61,8 & 55,7 \\
\hline Oro personol (\%) & - & - & - & - & - & - & - & - & 41,4 & 38,3 & 38,2 & 44,3 \\
\hline Gastos invernos en $1+D$ (miles de $\epsilon$ ) & 661.119 & 704.933 & 701.549 & 767.300 & 843.262 & 904.776 & 989.011 & 1.107 .815 & 1.261 .763 & 1.427 .504 & 1.738 .053 & 1.970 .823 \\
\hline \multicolumn{13}{|l|}{ A. Por naturaleza del gasto (\%) } \\
\hline Gastos corrientes & 81,1 & 79,3 & 83,2 & 85.0 & 83,6 & 80,7 & 80.7 & 79,1 & 79,5 & 807 & 81,4 & 79.6 \\
\hline Gastos de capilal & 18,9 & 20.6 & 16,8 & 15,0 & 16,4 & 19,3 & 19,3 & 20,0 & $x, 5$ & 19,3 & 18,6 & 20,4 \\
\hline \multicolumn{13}{|l|}{ 8. Por origen de los fondos (\%) } \\
\hline Financiación Pública & 87,1 & 87,7 & 85,4 & 83,3 & 83,7 & 83,5 & 83.2 & 84,1 & 83,5 & 84,2 & 85,7 & 87,2 \\
\hline De empresas & 5,3 & $5,3^{-}$ & 5.2 & 5,9 & 7,2 & 0,1 & 7,1 & 1,1 & 77 & 7,3 & 7,3 & 0,1 \\
\hline De universidades & 0,2 & 0,2 & 0,2 & 0,3 & 0,3 & 0,2 & 0,2 & 2,5 & 0,3 & 0,2 & 0,1 & 0,1 \\
\hline Do PSFI & 0,3 & 0,3 & 0,3 & 0,2 & 0,3 & 0,6 & 0,3 & 0.6 & 0,4 & 0.5 & 0,6 & 0.5 \\
\hline Del extianjero & 7,0 & 6,5 & 8,7 & 10,3 & 8,4 & 9,4 & 9,2 & 8.7 & 8.1 & 7,8 & 6,4 & 0,1 \\
\hline Gostos externos en $1+D$ (miles de $e$ ) & 30.465 & - & 29.942 & - & 84.761 & 49,151 & 65.529 & 53.463 & 69.65 & 75.691 & 90.721 & 145.982 \\
\hline
\end{tabular}

\begin{tabular}{|c|c|c|c|c|c|c|c|c|c|c|c|c|}
\hline \multicolumn{13}{|c|}{$\begin{array}{r}\text { I+D EN EL SECTOR EMPRESAS. } \\
\text { Principales variables }\end{array}$} \\
\hline & 1995 & 1996 & 1997 & 1998 & 1999 & 2000 & 2001 & 2002 & 2003 & 2004 & 2005 & 2000 \\
\hline$N^{2}$ de empresas que realizan I+D & 1.804 & - & 1.872 & - & 2.267 & - & 2.790 & 6.204 & 7.963 & 9.719 & 10.953 & 12.575 \\
\hline Personal empleado en $1+D(E C)$ & 27.555 & 29.430 & 30.023 & 34.667 & 38.323 & 47.055 & 46.465 & 56.337 & 65.032 & 71.123 & 75.345 & 82,870 \\
\hline hvestigodores $1 \%$ & 39,2 & 37,7 & 40,4 & 40.1 & 39,0 & 44,3 & 40.8 & 43.7 & 42,4 & 45.1 & 40.5 & 48.2 \\
\hline Otro personal (\%) & - & - & 20,1 & - & 22,4 & - & 19,6 & 56,3 & 57,6 & 54,9 & 53,5 & 51,8 \\
\hline Mujeres dedicadas a HD (ESC) & - & - & - & - & 8.608 & - & 9.129 & 15.716 & 17.793 & 20,194 & 21,351 & 24.194 \\
\hline Invesigadoras |\%| & - & - & - & - & - & - & - & 40,8 & 41,4 & 43,4 & 44,7 & $\Delta 6,5$ \\
\hline Otro personal (1\%) & - & - & - & - & - & - & - & 59.2 & 58.6 & 50,0 & 55,3 & 53,5 \\
\hline Gostos internos en I+D (miles de $€$ ) & 1.712 .229 & 1.862 .621 & 1.970 .851 & 2.457 .184 & 2.597 .099 & 3.068 .994 & 3.261 .031 & 3.926 .338 & 4. 443.438 & 4.864 .931 & 5.485 .033 & 6.557 .529 \\
\hline \multicolumn{13}{|l|}{ A. Por nafuraleza del gasto (\%) } \\
\hline Gostos corrientes & 83,3 & 86.2 & 81,8 & 79,4 & 80,0 & 84,1 & 79.6 & 86.5 & 83,3 & 80,0 & 83,3 & 81.6 \\
\hline Gostos de copitol & 16,8 & 13,7 & 18,2 & 20,6 & 20,0 & 15,9 & 20,4 & 13,5 & 16,7 & 14,0 & 16,7 & 18,4 \\
\hline \multicolumn{13}{|l|}{ B. Por origen de los fondas (\%) } \\
\hline Fondos propios & 80,3 & 83.0 & 80,2 & 83.1 & 81.7 & 88,8 & 78.0 & 73.8 & 75,9 & 74,9 & 73.3 & 12.0 \\
\hline De otras empresas: & 4,0 & 3,7 & 4,6 & 5,9 & 5,0 & - & 3,8 & 10,2 & 7,6 & 7,2 & 6,7 & 6,4 \\
\hline De la Adminisstroción Pública & 9,2 & 7,9 & 8,7 & 6,5 & 8,5 & 7,2 & 9,5 & 9,5 & 11,1 & 12,5 & 13,0 & 14,4 \\
\hline De universidades & 0.03 & 0,01 & 0.01 & 0.1 & 0.1 & 0.2 & 0.2 & 0.4 & 0,02 & 0,1 & 0,03 & 0,04 \\
\hline De IPSFL & 0,04 & 0,2 & 0,1 & 0.1 & 0,1 & - & 0,2 & 0,2 & 0,2 & 0,2 & 0,0 & 0,2 \\
\hline Del extranjero & 6,4 & 5,2 & 6,3 & 4,2 & 4,5 & 3,8 & 7,7 & 5,9 & $\$, 2$ & 5,1 & 5.8 & 0,3 \\
\hline Gustos exlernos en I+D (miles de $\in$ ) & 360.944 & - & 497.920 & - & 787.849 & - & 1.015 .165 & - & 1.410 .800 & 1.568 .287 & 1.792 .179 & 1.862 .963 \\
\hline
\end{tabular}




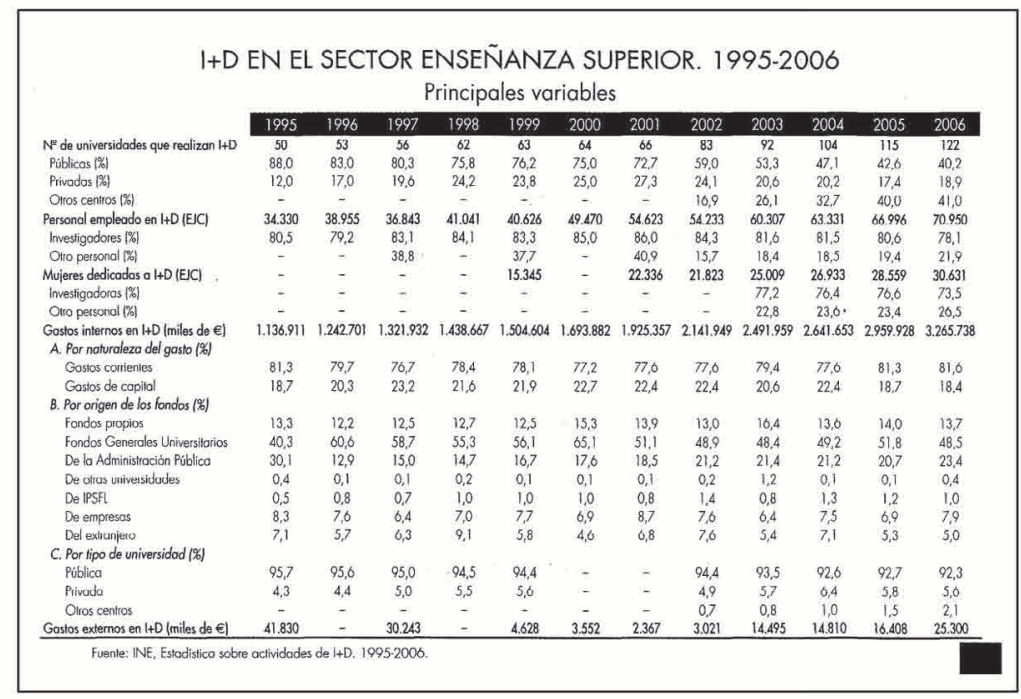

\begin{tabular}{|c|c|c|c|c|c|c|c|c|c|c|}
\hline \multicolumn{11}{|l|}{$1+D$} \\
\hline & \multicolumn{5}{|c|}{ Principales variables (1) } & & \\
\hline & 1995 & 1997 & 1999 & 2000 & 2001 & 2002 & 2003 & 2004 & 2005 & 2006 \\
\hline $\mathrm{N}^{2}$ de IPSFL que realizan I+D & 61 & 59 & 65 & 71 & 71 & 37 & 44 & 49 & 52 & 52 \\
\hline Personal empleado en $1+D(E)$ & 946 & 1.095 & 1.005 & 1.692 & 1.195 & 477 & 389 & 313 & 356 & 570 \\
\hline Investigadores $(\%)$ & 54,3 & 67,1 & 61,2 & 60,7 & 67,9 & 70,1 & 66,3 & 55,3 & 59,8 & 62,6 \\
\hline Otros $|\%|$ & - & 42,7 & 40,5 & - & 52,5 & 29.9 & 33,7 & 44,7 & 40,2 & 37,4 \\
\hline Mujeres dedicadas a $l+D(E I C)$ & - & - & - & - & - & - & 230 & 192 & 208 & 300 \\
\hline Investigadoras $|\%|$ & - & - & - & - & - & - & 63,3 & 52,6 & 59,6 & 56,1 \\
\hline Otro personal $(\%)$ & - & - & - & - & - & - & 36,7 & 47,4 & 40,4 & 43,9 \\
\hline Gastos internos en I+D (miles de euros) & 39.847 & 44.571 & 50.401 & 51.336 & 51.758 & 17.435 & 15.876 & 11.674 & 13.857 & 21.127 \\
\hline \multicolumn{11}{|l|}{ A. Por noturaleza del gasto (\%) } \\
\hline Gastos corrienles & 80,0 & 85,0 & 82,1 & 89,2 & 81,6 & 90,8 & 88,5 & 88,6 & 88,2 & 90,6 \\
\hline Gastos de capital & 20,0 & 15,0 & 17,8 & 10,8 & 18,4 & 9,2 & 11,5 & 11,4 & 11,8 & 9.4 \\
\hline \multicolumn{11}{|l|}{ B. Por origen de fondos $(\%)$} \\
\hline Fondos plopios & 48,5 & 30,4 & 38,3 & 53,9 & 56,6 & 25,4 & 25,2 & 35,7 & 28,0 & 29,1 \\
\hline Do la Administración Pública & 32,4 & 34,6 & 28,3 & 20,3 & 18,2 & 19,9 & 22,4 & $=24,4$ & 29,1 & 25,9 \\
\hline De empresas & 15,7 & 26,1 & 22.6 & 18.7 & 20.1 & 38,8 & 37.1 & 13,5 & 21.8 & 25,2 \\
\hline De universidades & 0,5 & 0,1 & 0,5 & 0,3 & 0,3 & 1,1 & 0,4 & 1,0 & 0,5 & 0.1 \\
\hline De IPSFL & - & - & - & - & - & 9,0 & 8,9 & 8,6 & 13,7 & 13,4 \\
\hline Del extranjero & 2,7 & 6,0 & 8,5 & 4,4 & 3,5 & 5,8 & 0,0 & 16,8 & 6,9 & 6,3 \\
\hline Gastos externos en 1+D (miles de euros) & 8.528 & 4.357 & 6.353 & 22.316 & 15.467 & 1.314 & 2.255 & 2.096 & 2.862 & 3.002 \\
\hline \multicolumn{11}{|c|}{$\begin{array}{l}\text { (1) Dalos de } 1996 \text { y } 1998 \text { no disponibles. } \\
\text { Fuente: INE. Fstradistica sobre aclividades de 1+D. } 19\end{array}$} \\
\hline
\end{tabular}




\begin{tabular}{|c|c|c|c|c|c|c|c|c|}
\hline \multicolumn{9}{|c|}{$\begin{array}{r}\text { INNOVACIÓN TECNOLÓGICA EN LAS EMPRES } \\
\text { Principales variables }\end{array}$} \\
\hline Años & $\begin{array}{l}\text { No empresas } \\
\text { innoradoras }\end{array}$ & $\begin{array}{l}\text { \% Empresas } \\
\text { innovadoras } \\
\text { respecto del total }\end{array}$ & $\begin{array}{l}\text { Empresas con } \\
\text { actividades } \\
\text { innovadoras }^{14}\end{array}$ & $\begin{array}{l}\text { Gastos en } \\
\text { innovación } \\
\text { (millones } e \text { ) }\end{array}$ & $\begin{array}{l}\text { Intensidad } \\
\text { innovación }\end{array}$ & $\begin{array}{l}\text { Empresas } \\
\text { innovadoras } \\
\text { renlizan } 1+0\end{array}$ & $\begin{array}{l}\% \text { emprescis } \\
\text { realizon } 1+D \\
\text { sobre total } 1 \text { is }\end{array}$ & $\begin{array}{l}\text { \% affra negacios } \\
\text { productos nuevos } \\
\text { o mejorados }\end{array}$ \\
\hline \multicolumn{9}{|c|}{ EMPRESAS INDUSTRIALES } \\
\hline 2002 & 12.117 & 26.23 & 10.500 & $0.273,20$ & 1.29 & 3.785 & 0,96 & 15,00 \\
\hline 2003 & 11.303 & 24,68 & 10.085 & 6.212 .54 & 1,40 & 4.855 & 10,60 & 13,34 \\
\hline 2004 & 16.553 & 34,36 & 13.074 & 0.919 .70 & 1,42 & 5.313 & 11,03 & 15,38 \\
\hline 2005 & 17.214 & 36,57 & 12.030 & $7.675,67$ & 1,31 & 5.650 & 12,00 & 25,30 \\
\hline $2006^{(1)}$ & 15.706 & 33,25 & 12.705 & $8.108,27$ & 1,29 & 0.169 & 13,06 & 18,96 \\
\hline \multicolumn{9}{|c|}{ TOTAL EMPRESAS } \\
\hline 2002 & 32.339 & 20,04 & 24.463 & $11.089,51$ & 0,83 & 5.526 & 2,90 & 8,60 \\
\hline 2003 & 31.711 & 19,36 & 23.721 & $11.198,51$ & 0,85 & 7.535 & 4,60 & 7,88 \\
\hline 2004 & 51.310 & 29,74 & 36.480 & $12.490,81$ & 0,82 & 8.958 & 5,19 & 11,95 \\
\hline 2005 & 47.529 & 27,00 & 29.766 & $13.365,95$ & 0,83 & 9.738 & 5,53 & 15,55 \\
\hline $2006^{11}$ & 49.415 & 25,33 & 31,460 & $16,533,42$ & 0,88 & 11.198 & 5,74 & 13,26 \\
\hline \multicolumn{9}{|c|}{ 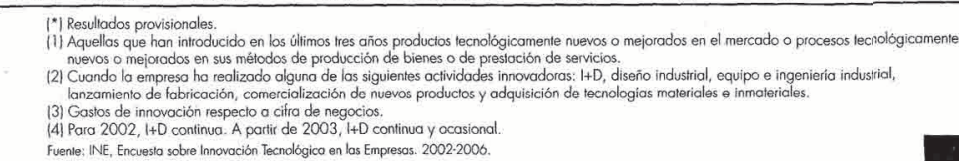 } \\
\hline
\end{tabular}

\begin{tabular}{|c|c|c|c|c|c|c|c|c|c|}
\hline \multicolumn{10}{|c|}{$\begin{array}{c}\text { NÚMERO DE EMPRESAS INNOVADORAS Y GASTO TOTAL EN INNOVACIÓN } \\
\text { POR RAMAS DE ACTIVIDAD. } 2006^{(*)}\end{array}$} \\
\hline 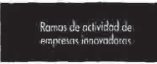 & 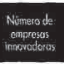 & 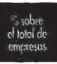 & 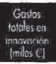 & $\begin{array}{l}\text { Gostos } \\
\text { schingel } \\
\text { torde }\end{array}$ & 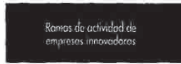 & 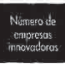 & 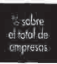 & 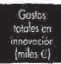 & $\begin{array}{l}\text { 3. Gonles } \\
\text { solige el } \\
\text { tolod }\end{array}$ \\
\hline Agriasilura & 1.442 & 29 & 136.944 & 0,8 & Apcrabs de roctio, television y comvinioxión & 113 & 0,2 & 161.071 & 1,0 \\
\hline Extroctivos & 153 & 0,3 & 37,132 & 0,2 & Instumentos úplico y relojerría & 346 & 0,7 & 13444 & 0.8 \\
\hline Alimerloción, bebidas y yoboco & 2,189 & $\triangle A$ & 398.856 & 3,6 & Autromoulles & 306 & 0,7 & 1480728 & 9,0 \\
\hline Textles & 593 & 1,2 & 87.353 & 0,5 & Navol & 113 & 0,2 & 78.100 & 0.5 \\
\hline Contección y peletería & 390 & 0.8 & 78.751 & 0.5 & Aerospaciol & 41 & 0,1 & 837.384 & 5,1 \\
\hline Cuero y colzado & 305 & 0.6 & 25.958 & 0.2 & Orro materiol de transpotite & 56 & 0.1 & 101.764 & 0.6 \\
\hline Modera y corcho (excepta muebles) & 603 & 1,2 & 60.825 & 0,4 & Muebles & 962 & 1,9 & 88700 & 0.5 \\
\hline Gorḱn ypopel & 295 & 0.6 & 127.678 & 0,8 & Oras manufocturas & 180 & 0,4 & 37.670 & 0.2 \\
\hline Edicion, impresión y reproducción & 957 & 1,8 & 255.894 & 1,5 & Recidaie & 31 & 0.1 & 15.224 & 0.1 \\
\hline Coque, peridleo y comb. mucleor & 8 & 0,0 & 119,424 & 0.7 & Electicidod, gos y ogvo & 159 & 0,3 & 253.858 & 1.5 \\
\hline Quitrica (excegpo furmaciol & 818 & 1,6 & 440.192 & 2,7 & Construcción & 10.721 & 21.5 & 421.068 & 2,0 \\
\hline Famacio & 197 & 0,4 & 949.445 & 5.7 & Conercio y hostederio & 10.385 & 20,8 & $055.10 \%$ & 40 \\
\hline Couchoy plestico & 834 & 1,7 & 228.290 & 1,4 & Trensportes y olmocenarientio & 1.490 & 3,0 & 1.200 .824 & 7,3 \\
\hline Minerolas no melaticos & 1.248 & 2,5 & 321.322 & 1,9 & Correos y thelecomunicociones & 232 & 0,5 & 2.063 .802 & 12,5 \\
\hline Netales tín reos & 182 & 0.4 & 150.851 & 0,9 & Intermediociön fronciero & 548 & 1,1 & $583.69 ?$ & 3,5 \\
\hline Melales no férreos & 130 & 0,3 & 61.913 & 0,4 & Progromas de ordenador & 926 & 1,9 & $646,47 ?$ & 3,9 \\
\hline Manuflacturas metälicas & 2,418 & 4,8 & 457.136 & 2,8 & Otros octividodes intomáticos & 193 & 0,4 & 48.314 & 0,3 \\
\hline Moquinorio y equipo meconico & 1.417 & 2,8 & 473.276 & 2,9 & Servicos da tiv & 234 & 0,5 & 1.353 .980 & 8,2 \\
\hline Maq. ohicina, éslulo y ordenadores & 37 & 0,1 & 79.335 & 0,5 & Servicios a empreseos & 4778 & 9,6 & 890.034 & 5,4 \\
\hline Maquinos electricas & 436 & 0,9 & 318.303 & 1,9 & Servicios píblicos, scíales y oolectives & 2.759 & 5,5 & 418.223 & 2,5 \\
\hline Componentes electrónicos & 101 & 0,2 & 47.386 & 0.3 & TOTA & 49.415 & 100,0 & 16.533 .416 & 100,0 \\
\hline $\begin{array}{l}\text { (") Resulitados p } \\
\text { Fuente: INE, Encue }\end{array}$ & $\begin{array}{l}\text { nales. } \\
\text { re innov }\end{array}$ & Tecnols & an las $E m$ & s, 2006 & & & & & \\
\hline
\end{tabular}




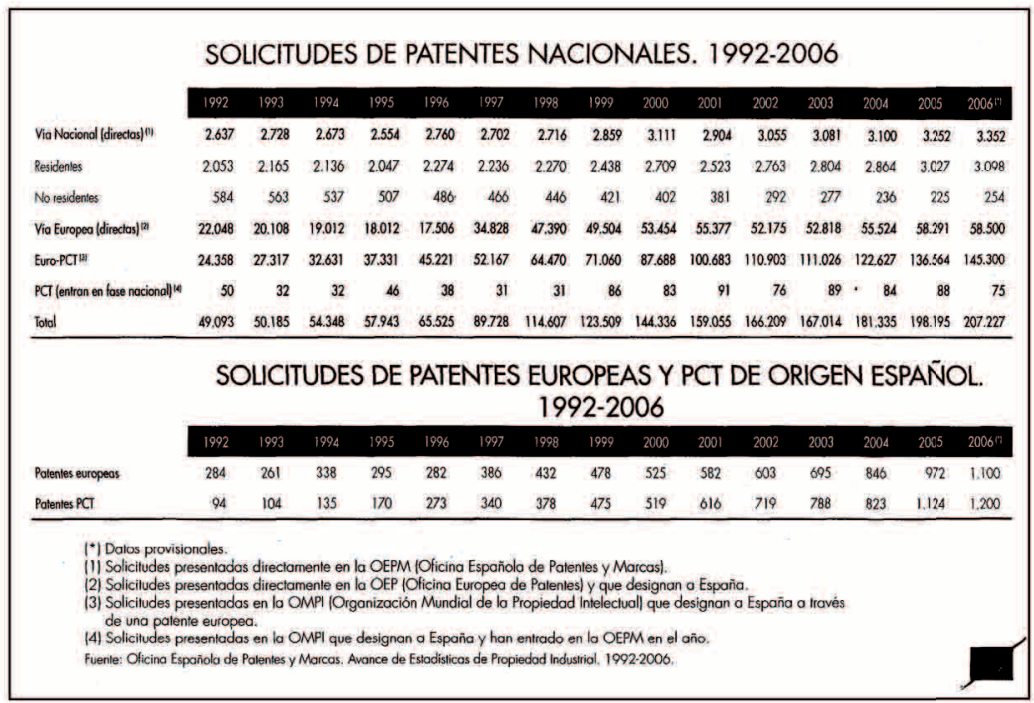

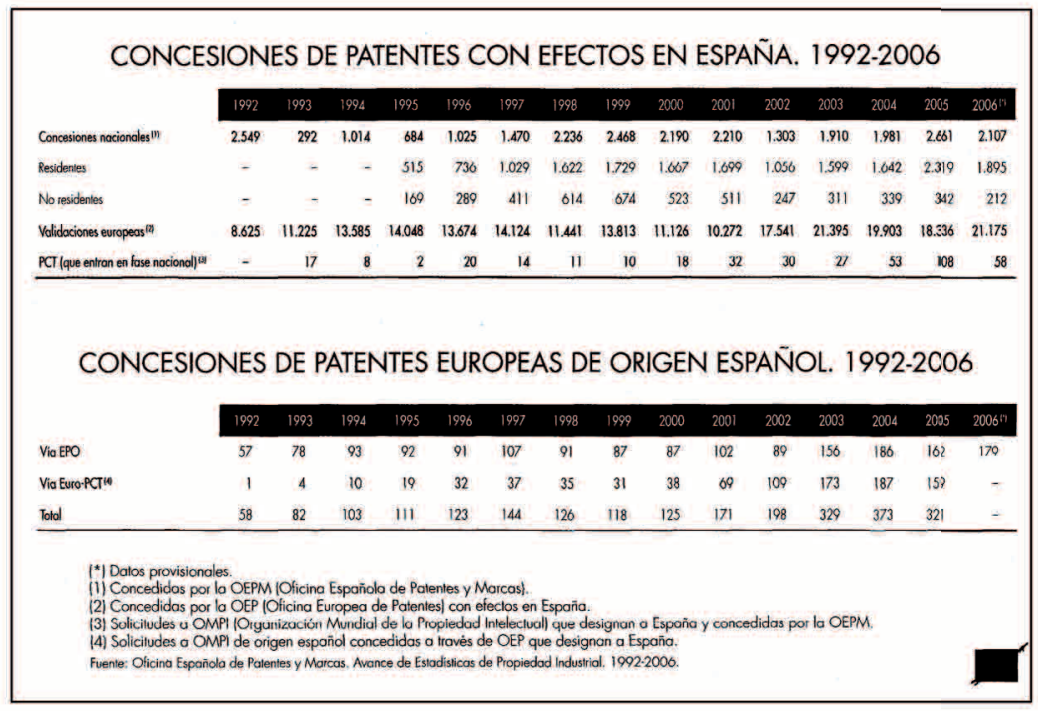




\begin{tabular}{|c|c|c|c|c|c|c|c|c|c|c|c|c|c|c|c|c|c|}
\hline \multicolumn{18}{|c|}{$\begin{array}{r}\text { GASTOS INTERNOS TOTALES EN I+D POR COML } \\
1990-2006 \\
\text { Miles de euros corrientes }\end{array}$} \\
\hline Canunidatuss Autbonomas & 1990 & 1991 & 1992 & 1993 & 199. & 1995 & $1996^{\circ}$ & 1997 & 1998 & 1999 & 2000 & 2001 & 2002 & 2003 & 2004 & 2005 & 2006 \\
\hline Andalucio & 180805 & 214411 & 250111 & 313.987 & 270.084 & 34.680 & 370.142 & 2305857 & 445400 & 474727 & 542156 & 538.332 & 585.667 & 903.152 & 882.013 & 1051.028 & 1.213 .815 \\
\hline Arogón & 56.032 & 58.548 & 82.803 & 87.501 & 81.21 & 87.,A95 & 87087 & 85.272 & 119704 & 136170 & 134.169 & 139.582 & 180.346 & 109.086 & 180.015 & 5221.261 & 203.428 \\
\hline Asturias & 40.112 & 48.958 & 51.435 & 51.970 & 48.147 & 57.097 & 03.005 & 61.147 & 68.419 & 74441 & 114586 & 99.022 & 98933 & 113279 & 116252 & 137.810 & 188.113 \\
\hline Boleares & 6599 & 8.901 & 8.961 & 8.805 & 11.684 & 16.714 & 21.372 & 25705 & 34.552 & 32867 & 34.853 & 38.404 & 45.221 & 46.323 & 54.687 & 01.505 & 70055 \\
\hline Canorios: & 28855 & 37.503 & 67145 & Q7 $\$ 46$ & 8n.277 & 71.053 & 86.377 & 82.140 & 106.151 & 104702 & 119.432 & 136.092 & 173098 & 188.449 & 199.295 & 214.217 & 254510 \\
\hline Conotic & 15987 & 19791 & 20.056 & 25.759 & 28.422 & 30.189 & 30.465 & 35.045 & $54 \pi 7$ & 42077 & 35.942 & 46.314 & 48.348 & 43.745 & 46.158 & 31.574 & 98.100 \\
\hline Casilloyloon & 95.146 & 103.795 & 124.824 & 100.000 & 155.530 & 134.224 & 144.117 & 150.273 & 158631 & 201.994 & men11 & 2059013 & 317.673 & 360728 & 423.081 & 436.552 & 511335 \\
\hline Custlo- to Mancha & 15500 & 20.549 & 25.146 & 27.370 & 28.151 & 06.598 & $\infty \pi x$ & 90.256 & 89.899 & 65.102 & 118.578 & 22211 & 105.296 & 110.905 & 116.589 & 126.589 & 155.703 \\
\hline Cordunia & 487295 & 563.305 & 604.300 & 652.016 & 659.500 & 772100 & 8147.74 & 87780 & 1.075 .340 & 1.120750 & 1.262 .108 & 1.333 .896 & 1.828 .042 & 1875.855 & 2.105 .970 & 2302.350 & 2614.383 \\
\hline Convinidod Vleterciana & 88.572 & 130053 & 191.302 & 194740 & 208.203 & 208.994 & 244.456 & 204271 & 313.897 & 332185 & 430512 & 446565 & 547944 & 631.986 & 731.940 & 867.066 & 913.160 \\
\hline Extemodura & $15.7 \pi$ & 16060 & 23.053 & 22.304 & 28.187 & 21.384 & 27.995 & 33.134 & 38.531 & 38675 & 56.537 & 60.294 & 71.380 & 80.852 & 58.947 & 109250 & 117288 \\
\hline Galicio & 52528 & 65005 & 101.024 & 93.427 & 84562 & 118.105 & 123.274 & 142.073 & 152.885 & 105.082 & 209.457 & 240.205 & 293.195 & 338.446 & 306.290 & 405.196 & 480.522 \\
\hline Motid & 1.133 .066 & 1.222272 & 1.253780 & 1.218 .264 & 1.221 .583 & 1.206 .327 & 1.282 .878 & 1.301 .071 & 1.456 .391 & 1569.413 & 1.751963 & 1.974 .212 & 2277822 & 7340.280 & 2400.405 & 2913.163 & 3.415991 \\
\hline Murcia & 31.337 & 31.697 & 51.495 & 49.271 & 44.216 & 50.792 & 52.967 & 60.042 & 09753 & 84.568 & 104.210 & 100.989 & 97.633 & 134.403 & 138.267 & 170.099 & 192510 \\
\hline Novare & 43958 & 50.677 & 57451 & 54008 & 46.807 & 55.407 & 60.191 & 62520 & 76.107 & 91.149 & QASOS & rusoss & 130881 & 177914 & 250.947 & 257.98 & 316.978 \\
\hline Pais Vasco & 217.831 & 250.838 & 253.880 & 272439 & 256.242 & 321.013 & 3537.02 & 357.380 & 416.284 & 414.085 & 459.617 & 561.104 & 581744 & 067.281 & 778.43 & 829.025 & 950.393 \\
\hline \&iopo & 2849 & 5048 & 5271 & 9027 & 8.054 & 11.760 & 13.379 & 14.202 & 19.900 & 20.296 & 27377 & 23.268 & 29.489 & 36.085 & 41.173 & 44.194 & 75127 \\
\hline No regionolzado & 26.270 & 31.992 & 33.110 & 34168 & 32.023 & - & - & - $\quad-$ & - $\quad-$ & - & - & . & 788 & 1.064 & 2400 & 3.424 & 5.202 \\
\hline Tolol & 2.559 .284 & 2831.084 & 324.979 & 3.350 .060 & 3.294 .472 & 3.550 .106 & 3.852 .632 & 10039.904 & 4.75 .018 & 4955360 & 5.778 .988 & 5.227.157 & 7.193 .540 & 8213.036 & 8965761 & 10196871 & 11.815218 \\
\hline & & & 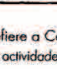 & es dete. & illa. & & & & & & & & & & & & \\
\hline
\end{tabular}

\section{GASTOS INTERNOS TOTALES EN I+D POR COMUNIDADES AUTÓNOMAS. 1990-2006}

Miles de euros constantes 1990

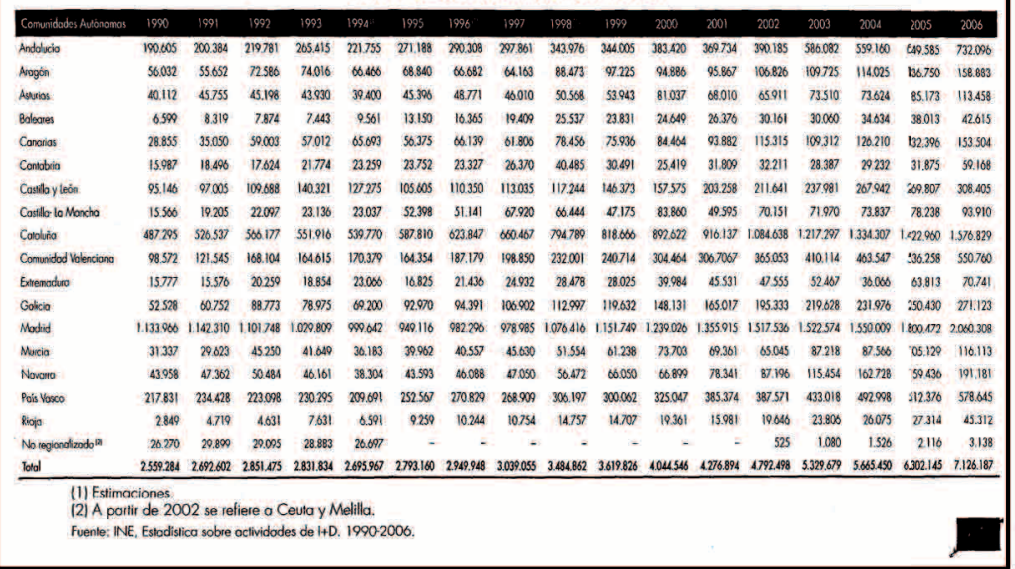




\begin{tabular}{|c|c|c|c|c|c|c|c|c|c|c|c|c|c|c|c|c|c|}
\hline \multicolumn{18}{|c|}{$\begin{array}{r}\text { GASTOS INTERNOS TOTALES EN I+D POR CON } \\
1990-2006 \\
\text { Estructura porcentual }\end{array}$} \\
\hline Comunidodes Aviónomas & 1990 & 1991 & 1992 & 1993 & 1994 & 1995 & 1996 & 1597 & $1998^{31}$ & 1999 & 2000 & 2001 & 2002 & 2003 & 2004 & 2005 & 2006 \\
\hline Andolucio & 7,4 & 7,4 & 777 & 9,4 & 8,2 & 9,7 & 9,8 & 9,8 & 9,9 & 9,5 & 9.5 & 8,6 & 8,1 & 11,0 & 9,9 & 10.3 & 10,3 \\
\hline Arogón & 2,2 & 2,1 & 2,5 & 2,6 & 2,5 & 2,5 & 2,3 & 2,1 & 2,5 & 2,7 & 2,3 & 2,2 & 2,2 & 2,1 & 2,0 & 2,2 & 2,2 \\
\hline Astuios & 1.6 & 1.7 & 16 & 1.6 & 1.5 & 1.6 & 17 & 1.5 & 1.5 & 1,5 & 2.0 & 1.6 & 1.4 & 1,4 & 1,3 & 1,4 & 1,6 \\
\hline Boloares & 0,3 & 0,3 & 0,3 & 0,3 & 0,4 & 0,5 & 0,6 & 0,6 & 0,7 & 0,7 & 0,6 & 0,6 & 0,6 & 0,0 & 0.6 & 0,6 & 0,6 \\
\hline Conolias & 1,1 & 1,3 & 2,1 & 2,0 & 2,4 & 2,0 & 2,2 & 2,0 & 2,3 & 2,1 & 2,1 & 2,2 & 2,4 & 2,1 & 2,2 & 2,1 & 2,2 \\
\hline Connobric & 0.6 & 0,7 & 0.6 & 0,8 & 0,9 & 0,9 & 0,8 & 0,9 & 1,2 & 0,8 & 0,6 & 0,7 & 0,7 & 0.5 & 0.5 & 0,5 & 0,8 \\
\hline Castllo y león & 3,7 & 3,6 & 3,8 & 5,0 & 4,7 & 3,8 & 3,7 & 3,7 & 3,4 & 4,0 & 3,9 & 4,8 & 4,4 & 4,5 & 4,5 & 4,3 & 4,3 \\
\hline Cosillo lo Mando & 0,6 & 0.7 & 0.8 & 0.8 & 0.9 & 1.9 & 17 & 2,2 & 1,9 & 1,3 & 2,1 & 1,2 & 1.5 & 1,4 & 1,3 & 1,2 & 1,3 \\
\hline Cobluño & 19,0 & 19,0 & 19,9 & 19,5 & 20,0 & 21,0 & 21,1 & 21,7 & 22,8 & 22,6 & 22,1 & 21,4 & 22,6 & 22,8 & 23.6 & 22,6 & 22.2 \\
\hline Correnidad Vdlencian & 3,9 & 4,5 & 5,9 & 5,8 & 6,3 & 5,9 & 6,3 & 0,5 & 6,7 & 0,0 & 7,5 & 7,2 & 7,6 & 7,7 & 8,2 & 8,5 & 7,7 \\
\hline Extemodura & 0,6 & 0.6 & 0,7 & 0,7 & 0,9 & 0,6 & 0.7 & 0,8 & 0.8 & 0.8 & 1.0 & 1,1 & 1,0 & 1.0 & 0.6 & 1,0 & 1.0 \\
\hline Galicio & 2,1 & 2,3 & 3,1 & 2,8 & 2,6 & 3,3 & 3,2 & 3,5 & 3,2 & 3,3 & 3,7 & 3,9 & 4,1 & 4,1 & 4,1 & 4,0 & 3,8 \\
\hline Modid & 44,3 & 42,4 & 38,6 & 36,4 & 37.1 & 34,0 & 33,3 & 32,2 & 30,9 & 31,8 & 30,6 & 31,7 & 31,7 & 28,6 & 27,4 & 28,6 & 28,9 \\
\hline Mucia & 1.2 & 1,1 & 1,0 & 1,5 & 1,3 & 1.4 & 1.4 & 1.5 & 1.5 & 1,7 & 1,8 & 1,6 & 1,4 & 1.6 & 1.5 & 1,7 & 1.6 \\
\hline Navarto & 1,7 & 1,8 & 1,8 & 1,6 & 1,4 & 1,6 & 1,6 & 1,5 & 1,6 & 1,8 & 1,7 & 1,8 & 1,8 & 2,2 & 2,9 & 2,5 & 2,7 \\
\hline Poís Vasco & 8,5 & 87 & 7,8 & 8.1 & 7.8 & 9,0 & 9,2 & 8,8 & 8,8 & 8,3 & 8,0 & 9,0 & 8.1 & 8,1 & 8,7 & 8,1 & 8,1 \\
\hline Riojo & 0,1 & 0,2 & 0,2 & 0,3 & 0,2 & 0,3 & 0,3 & 0.4 & 0,4 & 0,4 & 0,5 & 0,4 & 0,4 & 0,4 & 0,5 & 0.4 & 0,6 \\
\hline $\mathrm{Nb}$ regionolzado ${ }^{12}$ & 1,0 & 1,1 & 1,0 & 1,0 & 1,0 & - & - & - & - & - & - & - & 0,0 & 0,0 & 0,0 & 0,0 & 0,0 \\
\hline Iolal & 100,0 & 100,0 & 100,0 & 100,0 & 100,0 & 100,0 & 100,0 & 100,0 & 100,0 & 100,0 & 100,0 & 100,0 & 100,0 & 100,0 & 100,0 & 100,0 & 100,0 \\
\hline \multicolumn{18}{|c|}{$\begin{array}{l}\text { (1) Estimaciones. } \\
\text { (2) A partir de } 2002 \text { se refiere a Ceuta y Melilla. } \\
\text { Fuente: INE, Esiadistica sobre actividades de 1+D. 1990-2006. }\end{array}$} \\
\hline
\end{tabular}

GASTOS INTERNOS TOTALES EN I+D POR COMUNIDADES AUTÓNOMAS. $1991-2006$

Tasas de variación interanual (\%)

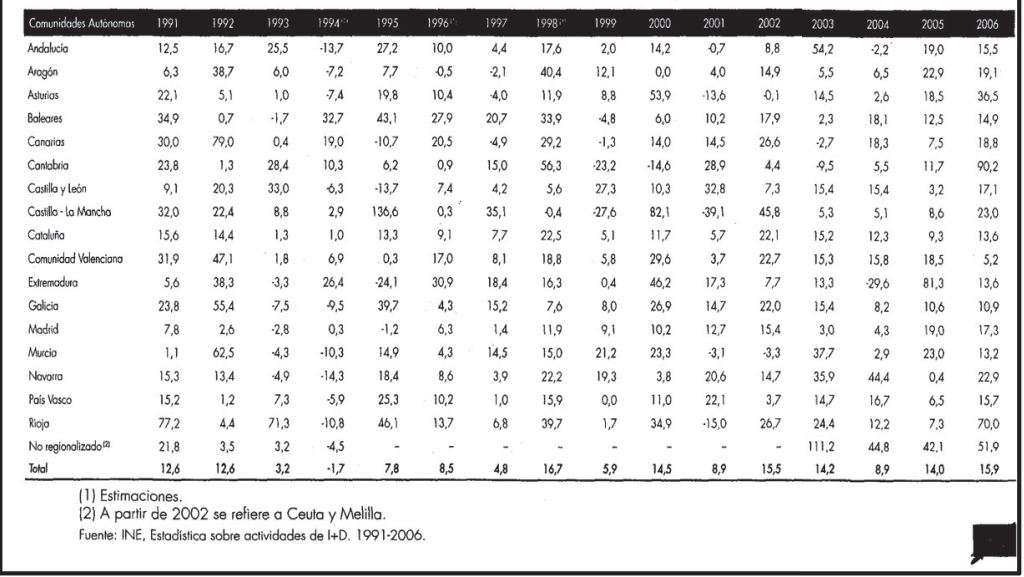


GASTOS INTERNOS TOTALES EN I+D POR COMUNIDADES AUTÓNOMAS. 1995-2006

En porcentaje del PIB regional

\begin{tabular}{|c|c|c|c|c|c|c|c|c|c|c|c|c|}
\hline Comunidades Autóncmas & 1995 & 1996 & 1997 & 1998 & 1999 & 2000 & 2001 & 2002 & 2003 ता & 2004 & 2005 (1) a) & $2006^{(3118)}$ \\
\hline Andalucia & 0,59 & 0,02 & 0,00 & 0,00 & 0,63 & 0,06 & 0,01 & 0,02 & 0,89 & 0,77 & 0.84 & 0,90 \\
\hline Aragón & 0,01 & 0,57 & 0,53 & 0,71 & 0,76 & 0,71 & 0,69 & 0,75 & 0,74 & 0,70 & 0,79 & 0,88 \\
\hline Asturios & 0,53 & 0,57 & 0,53 & 0,56 & 0,59 & 0,83 & 0,68 & 0,65 & 0,70 & 0.64 & 0,70 & 0,90 \\
\hline Baleares & 0,17 & 0,21 & 0,22 & 0,28 & 0.24 & 0,23 & 0,23 & 0,20 & 0,25 & 0.20 & 0,28 & 0.29 \\
\hline Conarios & 0.45 & 0,50 & 0,43 & 0,51 & 0.46 & 0,49 & 0,52 & 0,60 & 0,55 & 0.58 & 0.59 & 0.05 \\
\hline Conbabia & 0,55 & 0.53 & 0,58 & 0,84 & 0,59 & 0,47 & 0.55 & 0,55 & 0,47 & 0,44 & 0,45 & 0,80 \\
\hline Costilla y león. & 0,50 & 0,52 & 0,52 & 0,52 & 0.62 & 0,64 & 0,80 & 0,81 & 0,88 & 0,93 & 0,89 & 0,97 \\
\hline Costillata Mancha & 0,43 & 0,40 & 0,52 & 0,48 & 0,33 & 0,56 & 0,33 & 0,44 & 0,44 & 0,41 & 0,41 & 0,47 \\
\hline Cotolunia & 0,90 & 0,92 & 0,94 & 1,09 & 1,07 & 1,12 & 1,11 & 1,28 & 1,38 & 1,34 & 1,35 & 1.43 \\
\hline Comunidod Valenciano & 0,50 & 0,50 & 0,50 & 0,62 & 0,61 & 0,73 & 0,70 & 0,81 & 0,87 & 0,90 & 0,99 & 0,96 \\
\hline Exrenaduro & 0,28 & 0,34 & 0,39 & 0,43 & 0.40 & 0,53 & 0,00 & 0,00 & 0,63 & 0,41 & 0,09 & 0,73 \\
\hline Galicia & 0,48 & 0,48 & 0,52 & 0,53 & 0,53 & 0,64 & 0,69 & 0,79 & 0,86 & 0,86 & 0,89 & 0,90 \\
\hline Madrid & 1,64 & 1,64 & 1.58 & 1,01 & 1,64 & 1,67 & 1,75 & 1,88 & 1,81 & 1.65 & 1,82 & 1,98 \\
\hline Murcio & 0,51 & 0,50 & 0,52 & 0,56 & 0,64 & 0,71 & 0,05 & 0,57 & 0,73 & 0,00 & 0.75 & 0,78 \\
\hline Novaro & 0,72 & 0,74 & 0,73 & 0,84 & 0,96 & 0,91 & 1.04 & 1.11 & 1,41 & 1.79 & 1.07 & 1.92 \\
\hline Pais Vosco & 1,17 & 1,23 & 1,15 & 1,24 & 1,14 & 1,17 & 1,34 & 1,32 & 1,42 & 1,51 & 1,48 & 1,60 \\
\hline Riojo & 0,36 & 0.39 & 0,38 & 0,50 & 0,47 & 0,59 & 0.47 & 0.57 & 0.66 & 0,00 & 0,66 & 1,06 \\
\hline Ceuto y Melillotin & - & - & - & - & - & - & - & 0,04 & 0,07 & 0,10 & 0,13 & 0.19 \\
\hline Totol & 0,81 & 0,83 & 0,82 & 0,89 & 0,88 & 0,94 & 0,95 & 1,03 & 1,10 & 1,06 & 1,12 & 1,20 \\
\hline \multicolumn{13}{|c|}{$\begin{array}{l}\text { (1) Ruplura de la serie por cambio metodológico llncluye I+D continua y ocasionall. } \\
\text { (2) Datos referidos al PIB } 2000=100 \text {. } \\
\text { (3) Hasta } 2002 \text { el dato de Andalucía incluye Ceuta y Melilla. }\end{array}$} \\
\hline \multicolumn{13}{|c|}{ Fuente: INE, Estadistica sobre actividades de 1+D. 1995-2006. } \\
\hline
\end{tabular}

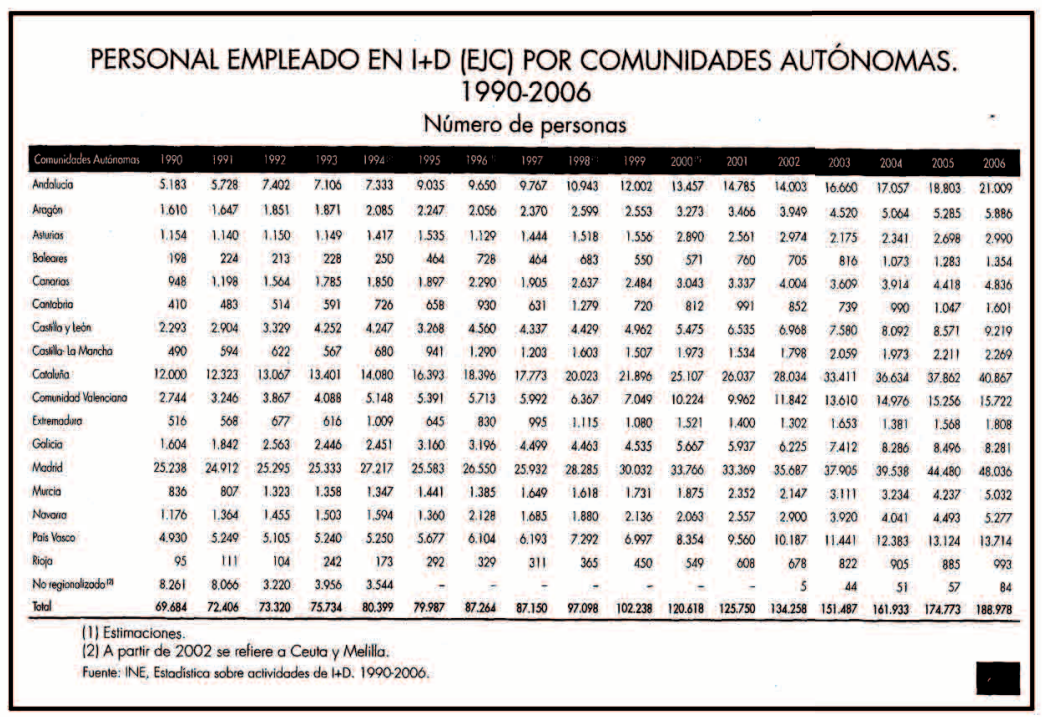




\begin{tabular}{|c|c|c|c|c|c|c|c|c|c|c|c|c|c|c|c|c|c|}
\hline \multicolumn{18}{|c|}{$\begin{array}{r}\text { PERSONAL EMPLEADO EN I+D (EJC) POR CON } \\
1990-2006 \\
\text { Estructura porcentual }\end{array}$} \\
\hline Cemvendodes Aditononoms & 1990 & 1991 & 1992 & 1993 & 1994 & 1995 & 1096 & 1997 & $1998:$ & 1999 & 2000 & 2001 & 2502 & 2003 & $200 \mathrm{n}$ & 2005 & 2006 \\
\hline Andalucio & 7,4 & 7,9 & 10,1 & 9,4 & $9 ; 1$ & 11,3 & 11,1 & 11.2 & 11,3 & 11,7 & 11,2 & 11,8 & 10,4 & 11,0 & 10,5 & 10,8 & 11,1 \\
\hline Áogán & 2,3 & 2,3 & 2,5 & 2,5 & 2,6 & 2,8 & 2,4 & 2,7 & 2,7 & 2,5 & 2,7 & 2,8 & 29 & 3,0 & 3,1 & 3,0 & 3,1 \\
\hline Asurios & 17 & 1,6 & 1,6 & 1.5 & 1,8 & 1.9 & 1,3 & 1,7 & 1,0 & 1,5 & 2,4 & 2,0 & 2,2 & 1,4 & 1,4 & 1,5 & 1,0 \\
\hline Bdeoces & 0,3 & 0.3 & 0,3 & 0,3 & 0,3 & 0,6 & 0,8 & 0,5 & 0,7 & 0,5 & 0,5 & 0,6 & 0,5 & 0,5 & 0,7 & 0,7 & 0,7 \\
\hline Conorios & 1,4 & 1,7 & 2,1 & 2,4 & 2,3 & 2,4 & 2,6 & 2,2 & 2,7 & 2,4 & 2,5 & 2.7 & 3,0 & 2,4 & 2,4 & 2.5 & 2,6 \\
\hline Contabia & 0,6 & 0,7 & 0,7 & 0,8 & 0,9 & 0,8 & 1,1 & 0.7 & 1,3 & 0,7 & 0,7 & 0,8 & 0,6 & $0, \dot{5}$ & 0,6 & 0,6 & 0,8 \\
\hline Cosilla y león & 3,3 & 4,0 & 4,5 & 5,6 & 5,3 & 4,1 & 5,2 & 5,0 & 4,6 & 4,9 & 4,5 & 5,2 & 5,2 & 5,0 & 5.0 & 4.9 & 4,9 \\
\hline Costihar lo Moncha & 0,7 & 0,8 & 0,8 & 0,7 & 0,8 & 1,2 & 1,5 & 1,4 & 1,7 & 1,5 & 1,0 & 1,2 & 1,3 & 1,4 & 1,2 & 1,3 & 1,2 \\
\hline Cotaluño & 17,2 & 17,0 & 17,8 & 17,7 & 17,5 & 20,5 & 21,1 & 20,4 & 20,6 & 21,4 & 20,8 & 20,7 & 20,9 & 22,1 & 22,6 & 21,7 & 21,6 \\
\hline Comunidad Volenciana & 3,9 & 4,5 & 5,3 & 5,4 & 6,4 & 6,7 & 6,5 & 6,9 & 6,6 & 6,9 & 8,5 & 7.9 & 8,8 & 9,0 & 9,2 & 8.7 & 8,3 \\
\hline Extrerroduro & 0,7 & 0,8 & 0,9 & 0,8 & 1,3 & 0.8 & 1,0 & 1,1 & 1,1 & 1,1 & 1,3 & 1,1 & 1,0 & 1,1 & 0,9 & 0,9 & 1,0 \\
\hline Golikio & 2,3 & 2,5 & 3,5 & 3,2 & 3,0 & 4,0 & 3,7 & 5,2 & 4,6 & 4,4 & 4,7 & 4,7 & 4,6 & 49 & 5,1 & 4,9 & 4,4 \\
\hline Modid & 36,2 & 34,4 & 34,5 & 33,4 & 33.9 & 32,0 & 30,4 & 29,8 & 29,1 & 29,4 & 28,0 & 26,5 & 26,6 & 25,0 & 24,4 & 25,5 & 25,4 \\
\hline Mucia & 1,2 & 1.1 & 1,8 & 1.8 & 1,7 & 1,8 & 1,6 & 1,9 & 1,7 & 17 & 1,6 & 1,9 & 1,6 & 2,1 & 2,0 & 2,4 & 2,7 \\
\hline Navoro & 1,7 & 1,9 & 2,0 & 2,0 & 2,0 & 1,7 & 2,4 & 1,9 & 1.9 & 2,1 & 1,7 & 2,0 & 2,2 & 2,6 & 2,5 & 2,6 & 2,8 \\
\hline Polis Vasco & 7,1 & 7.2 & 7.0 & 6,9 & 6.5 & 7.1 & 7,0 & 7.1 & 7.5 & 0,8 & 0,9 & 7,6 & 7,0 & 7,0 & 7,6 & 7,5 & 7,3 \\
\hline fioio & 0.1 & 0,2 & 0,1 & 0,3 & 0,2 & 0,4 & 0,4 & 0,4 & 0,4 & 0,4 & 0,5 & 0.5 & 0,5 & 0,5 & 0,6 & 0.5 & 0,5 \\
\hline No iegionolizodo at & 11,9 & 11,1 & 4,4 & 5,2 & 4,4 & - & - & - & - & - & - & - & 0,0 & 0,0 & 0,0 & 0,0 & 0,0 \\
\hline Total & 100,0 & 100,0 & 100,0 & 100,0 & 100,0 & 100,0 & 100,0 & 100,0 & 100,0 & 100,0 & 100,0 & 100,0 & 100,0 & 100,0 & 100,0 & 100,0 & 100,0 \\
\hline $\begin{array}{l}\text { (1) Estime } \\
\text { (2) A par } \\
\text { Fuente: IN }\end{array}$ & Estadis & ca sobre & 1 & $\begin{array}{l}\text { eula } y \\
\text { is de } 1+\end{array}$ & elilla. & & & & & & & & & & & & \\
\hline
\end{tabular}

\begin{tabular}{|c|c|c|c|c|c|c|c|c|c|c|c|c|c|c|c|c|c|}
\hline \multicolumn{18}{|c|}{$\begin{array}{r}\text { INVESTIGADORES (EJC) POR COMUNIDADES } \\
\text { Número de personas }\end{array}$} \\
\hline Comuricalss Autinomas & 1990 & 1991 & 1992 & 1993 & 1994 & 1995 & 1996 & 1997 & 1909 : & 1999 & 2000 & 2001 & 2002 & 2003 & 2004 & 2005 & 2005 \\
\hline Andalucio & 3.370 & 3.844 & 4.114 & 4.311 & 4.978 & 5.870 & 0.432 & 0.690 & 7.634 & 8.600 & 9.210 & 10.817 & 9.522 & 11.090 & 11.998 & 13.269 & 12.624 \\
\hline Arogón & 929 & 995 & 1.087 & 1.102 & 1.418 & 1.459 & 1.254 & 1.487 & 1.674 & 1.038 & 1.948 & 2.096 & 2.460 & 2.937 & 3.295 & 3.550 & 3.924 \\
\hline Astrios & 871 & 890 & 689 & 717 & 938 & 1.033 & 784 & 1.015 & 1.064 & 1.072 & 2.106 & 2.037 & 2.268 & 1.586 & 1.676 & 1.791 & 1.886 \\
\hline Boleares & 139 & 179 & 157 & 172 & 178 & 294 & 570 & 332 & 415 & 394 & 439 & 506 & 463 & 612 & 735 & 898 & 983 \\
\hline Canarios & 728 & 945 & 1.018 & 1.118 & 1.289 & 1.278 & .1 .661 & 1.374 & 2.045 & 1.785 & 2.380 & .2 .766 & 3.255 & 2.861 & 3.141 & 3.209 & 3.188 \\
\hline Canbotrio & 294 & 373 & 311 & 388 & 522 & 439 & 633 & 457 & 883 & 472 & 570 & 715 & 555 & 465 & $O B 2$ & 683 & 1.122 \\
\hline Casillo y león & 1.467 & 1.089 & 1.848 & 1.933 & 2.882 & 2.152 & 2.943 & 3.140 & 3.271 & 3.409 & 3.992 & 4.988 & 4.919 & 5.228 & 5.461 & 5.786 & 0.056 \\
\hline Casillo-ta Marcho & 226 & 301 & 329 & 352 & 438 & 518 & .554 & 621 & 855 & 773 & 1.070 & 953 & 951 & 1.258 & 1.199 & 1.336 & 1.310 \\
\hline Caldonio & 5.889 & 0.381 & 0.370 & 0.780 & 7.616 & 8.814 & 9.611 & 9.544 & 11.469 & 11.844 & 14.812 & 14.054 & 15.457 & 18.387 & 20.747 & 22.240 & 24.477 \\
\hline Comuridad Volenciano & 1.774 & 2.323 & 2.261 & 2.543 & 3.750 & 3.553 & 3.850 & 3.728 & 4.012 & 4.070 & 0.122 & 6.264 & 7.318 & 8.339 & 9.091 & 9.194 & 9.387 \\
\hline Extemoduo & 284 & 320 & 342 & 322 & 746 & 402 & 493 & 734 & 884 & 774 & 1.163 & 1.137 & 1.079 & 1.199 & 919 & 1.056 & 1.233 \\
\hline Galicio & 1.032 & 1.183 & 1.378 & 1.360 & 1.562 & 1.963 & 1.750 & 3.433 & 3.505 & 3.304 & 3.982 & 4.254 & 3.914 & 4.836 & 5.630 & 5.851 & 5.191 \\
\hline Modind & 13.393 & 13.488 & 13.965 & 13.889 & 13.215 & 14.603 & 14.985 & 15.520 & 15.778 & 16.812 & 20.715 & 19.775 & 21.095 & 21.624 & 23.662 & 26.553 & 28.100 \\
\hline Murcio & 545 & 558 & 627 & 765 & 925 & 901 & 871 & 1.007 & 1.044 & 1.066 & 1.185 & 1.443 & 1.283 & 2.001 & 2.235 & 2.003 & 3.704 \\
\hline Nowarro & 703 & 883 & 952 & 1.017 & 1.054 & 761 & 1.594 & 1.125 & 1.352 & 1.423 & 1.601 & 1.056 & 1.928 & 2.591 & 2.726 & 2.997 & 3.374 \\
\hline Poís losso & 2.544 & 2.820 & 2.719 & 2.842 & 2.065 & 3.108 & 3.405 & 3.486 & 4.160 & 3.790 & 5.039 & 5.563 & 6.476 & 7.020 & 7.242 & 8.165 & 8.629 \\
\hline Riopa & 36 & 37 & 33 & 146 & 150 & 196 & 245 & 190 & 224 & 282 & 337 & 399 & 373 & 448 & 507 & 482 & 525 \\
\hline No 1egionolizodolat & 3.653 & 3.647 & 3.481 & 3.588 & 3.544 & - & - & - & - & - & - & - & 3 & 41 & 48 & 47 & $\pi$ \\
\hline Tolal & 37.676 & 40.642 & 41.881 & 43.367 & 47.867 & 47.342 & 51.633 & 59.883 & 60.269 & 61.568 & 76.670 & 80.081 & 83.318 & 92.523 & 100.994 & 109.720 & 115.798 \\
\hline \multicolumn{18}{|c|}{$\begin{array}{l}\text { (1) Estimaciones. } \\
\text { (2) A partir de } 2002 \text { se refiere a Ceuta y Melilla. }\end{array}$} \\
\hline
\end{tabular}




\begin{tabular}{|c|c|c|c|c|c|c|c|c|c|c|c|c|c|c|c|c|c|}
\hline \multicolumn{18}{|c|}{$\begin{array}{r}\text { INVESTIGADORES (EJC) POR COMUNIDADES } \\
\text { Estructura porcentual }\end{array}$} \\
\hline Comunitadss Astonomos & 1990 & 1991 & 1992 & 1993 & 1994" & 1995 & 1996 & 1997 & $1998^{\circ}$ & 1999 & 2000 & 2001 & 2002 & 2003 & 20204 & 2005 & 2006 \\
\hline Andelucio & 8,9 & 9,5 & 9,9 & 9,9 & 10,4 & 12,4 & 12,5 & 12,4 & 127 & 14,1 & 12,0 & 13,5 & 11,4 & 12,0 & 11,9 & 12,0 & 10,9 \\
\hline Arroǵn & 2.5 & 2,4 & 2.6 & 2.5 & 30 & 3,1 & 2.4 & 2.8 & 2,8 & 2,7 & 2,5 & 2,6 & 30 & 3.2 & 3,3 & 3.2 & 3,4 \\
\hline Asturios & 1,8 & 17 & 17 & 1,7 & 20 & 2,2 & 1.5 & 1,9 & 1.8 & 17 & 27 & 2,5 & 2,7 & 1,7 & 17 & 1,6 & 1,0 \\
\hline Bolecues & 0.4 & 0,4 & 0,4 & 0,4 & 0.4 & 0,6 & 1.1 & 0,6 & 0.7 & 0,6 & 0,6 & 0.7 & 0,6 & 0,7 & 0.7 & 0,8 & 0,8 \\
\hline Cononos & 1.9 & 2,3 & 2,4 & 2,6 & 2,7 & 2.7 & 3,2 & 2.5 & 3.4 & 2,9 & 3.1 & 3.5 & 3.9 & 3.1 & 3.1 & 29 & 2,8 \\
\hline Connabria & 0,8 & 0,9 & 0,7 & 0,9 & 1.) & 0,9 & 1,2 & 0,8 & 1,5 & 0,8 & 0,7 & 0,9 & 0,7 & 0,5 & 0,7 & 0,8 & 1,0 \\
\hline Costhlay leain & 3,9 & 4,2 & 4,4 & 4,5 & 8,0 & 4,5 & 5,7 & 5,8 & 5,4 & 5,5 & 5,2 & 0,2 & 5,9 & $\$, 7$. & 5,4 & 5,3 & 5.2 \\
\hline Costiba la Mancha & 0,6 & 0,7 & 0,8 & 0,8 & 0,9 & 1.1 & 1,1 & 1,2 & 1,4 & 1,3 & 1,4 & 1,2 & 1,1 & 1.4 & 1.2 & 1.2 & 1.1 \\
\hline Condwion & 15,6 & 157 & 15,3 & 15,6 & 15.9 & 18.6 & 18,6 & 177 & 19,0 & 19,2 & 19,3 & 18,3 & 18,6 & 19,9 & 20,5 & $: 0,3$ & 21,1 \\
\hline Comunidod Vlenciona & 47 & 5.7 & 5.4 & 5,9 & 7.8 & 7,5 & 7.5 & 0.9 & 0,7 & 0.6 & 8.0 & 7,8 & 8,8 & 9,0 & 9,0 & 8,4 & 8.1 \\
\hline Extemodiar & 0.8 & 0,8 & 0,8 & 0,7 & 1,6 & 0,8 & 1,0 & 1.4 & 1.5 & 1,3 & 1,5 & 1.4 & 1.3 & 1,3 & 0.9 & 1,0 & $1, \mathrm{I}$ \\
\hline Golicia & 2,7 & 2,9 & 3,3 & 3.2 & 3,3 & 4,1 & 3,4 & 0,4 & 5,8 & 5,4 & 5,2 & 5,3 & 4,7 & 5,2 & 5,6 & 5.3 & 4.5 \\
\hline Modid & 35,5 & 33,2 & 33,5 & 32,0 & 27,6 & 30,8 & 29,0 & 28,8 & 26,2 & 27,3 & 27.0 & 24,7 & 25,3 & 23,4 & 23,4 & 24,2 & 24,3 \\
\hline Morcia & 1,4 & 1,4 & 1,5 & 1,8 & 1,9 & 1,9 & 1,7 & 1,9 & 1.7 & 17. & 1.5 & 1.8 & 1.5 & 2,2 & 2.2 & 2,4 & 3.2 \\
\hline Norolita & 1.9 & 2,1 & 2,3 & 2,3 & 2,2 & 1,6 & 3.1 & 2,1 & 2,2 & 2.3 & 2.1 & 2.1 & 2,3 & 2.8 & 27 & 27 & 2,9 \\
\hline Pas Vosco & 0,8 & 6,9 & 0,5 & 0,6 & 5,6 & 0,6 & 0,6 & 0.5 & 6.9 & 0,2 & 6,6 & 6,9 & 7,8 & 7,6 & 7.2 & 7,4 & 7,5 \\
\hline riop & 0,1 & 0,1 & 0,1 & 0,3 & 0,3 & 0,4 & 0.5 & 0,4 & 0,4 & 0.5 & 0,4 & 0.5 & 0,4 & 0,5 & 0,5 & 0,4 & 0,5 \\
\hline No regiondizodo ${ }^{\text {th }}$ & 9,7 & 9,0 & 8,4 & 8,3 & 7,4 & - & - & - & - & - & - & - & 0,0 & 0,0 & 0,0 & 0,0 & 0,0 \\
\hline Iod & 100,0 & 100,0 & 100,0 & 100,0 & 100,0 & 100,0 & 100,0 & 100,0 & 100,0 & 100,0 & 100,0 & 100,0 & 100,0 & 100,0 & 100,0 & 100,0 & 100,0 \\
\hline \multicolumn{18}{|c|}{$\begin{array}{l}\text { (1) Estimaciones. } \\
\text { (2) A partir de } 2002 \text { se refiere a Ceula y Melillo. } \\
\text { fuente: INE, Estadística sabre actividades de l+D. 1990-2006. }\end{array}$} \\
\hline
\end{tabular}

\begin{tabular}{|c|c|c|c|c|c|c|c|c|c|}
\hline \multirow{2}{*}{\multicolumn{4}{|c|}{$\begin{array}{l}\text { GASTOS INTERNOS Y PERSON } \\
\text { POR COMUNIDADES AUTO } \\
\text { Comunidades }\end{array}$}} & \multirow{2}{*}{\multicolumn{3}{|c|}{$\begin{array}{r}\text { IAL EMPLEADO EN } \\
\text { NOMAS Y SECTO } \\
\text { Administración Püblica }\end{array}$}} & $\begin{array}{l}\text { /IDADES } \\
\text { ACTIVIDA }\end{array}$ & $\begin{array}{l}D E I+D \\
A D .2008\end{array}$ & EJC) \\
\hline & & & & & & & \multicolumn{3}{|c|}{ Enseñanza Superior } \\
\hline Aulonomas & $\begin{array}{l}\text { Gastos internos } \\
\text { (miles de } \Theta \text { ) }\end{array}$ & Personal en $1+D$ & Investigadores & $\begin{array}{l}\text { Gastos internos } \\
\text { (miles de } € \text { ) }\end{array}$ & Personal en $1+D$ & Investigadores & $\begin{array}{c}\text { Gasios internos } \\
\text { (miles de } 6 \text { ) }\end{array}$ & Personal en $1+D$ & nvestigadores \\
\hline Andalucia & 403.387 & 5.987 & 2.472 & 283.184 & 4.860 & 2.797 & 527.245 & 10.163 & 7,355 \\
\hline Aragón & 152.632 & 2.467 & 1.054 & 50.787 & 1.053 & 624 & 80.009 & 2.366 & 2.246 \\
\hline Asturias & 88.199 & 1.139 & 532 & 29.001 & 520 & 258 & 70.913 & 1.331 & 1.096 \\
\hline Boleares & 13.449 & 274 & 107 & 20.320 & 416 & 303 & 36.886 & 664 & 573 \\
\hline Canarios & 06.342 & 759 & 272 & 66.207 & 1.268 & 761 & 121.961 & 2.809 & 2.154 \\
\hline Cantabria & 33.696 & 626 & 377 & 15.560 & 318 & 220 & 48.844 & 657 & 525 \\
\hline Castilla y leán & 286.890 & 3.462 & 1750 & 42.209 & 909 & 527 & 182.235 & 4.817 & 3.780 \\
\hline Castillato Mancha & 75.868 & 905 & 369 & 21.142 & 323 & 191 & 58.694 & 1.041 & 750 \\
\hline Cataluño & 1.704 .962 & 21.760 & 10.345 & 311.393 & 5.547 & 3.700 & 598.028 & 13.555 & 10.432 \\
\hline Com. Valenciano & 348.610 & 5.817 & 2.512 & 109.353 & 2.145 & 1.399 & 455.198 & 7.760 & 5.475 \\
\hline Extrenaduro & 21.215 & 356 & 168 & 30.428 & 344 & 108 & 59.045 & 1.108 & 898 \\
\hline Galicia & 198.290 & 3.021 & 1.238 & 75.306 & 1.329 & 756 & 175.926 & 3.931 & 3.197 \\
\hline Madrid & 2.083 .220 & 22.122 & 11.487 & 796.935 & 13.794 & 7.163 & 535.836 & 12.120 & 9.451 \\
\hline Murcia & 84.058 & 1.208 & 540 & 36.214 & 726 & 444 & 72.244 & 3.098 & 2.720 \\
\hline Novarra & 214.851 & 2.891 & 1.366 & 23.888 & 249 & 182 & 78.239 & 2.136 & 1.826 \\
\hline País Vosco & 752.245 & 10.061 & 5.495 & 39.263 & 653 & 503 & 167.885 & 3.000 & 2.631 \\
\hline Ricja & 50.447 & 570 & 197 & 13.551 & 134 & 67 & 11,129 & 288 & 261 \\
\hline Ceuta y Melilla & 295 & 8 & 3 & 84 & 1 & 0 & 4.823 & 75 & 75 \\
\hline Total & 6.578 .656 & 83.440 & 40.293 & 1.970 .823 & 34.588 & 20.063 & 3.265 .738 & 70.950 & 55.443 \\
\hline
\end{tabular}




\begin{tabular}{|c|c|c|c|c|c|c|c|c|c|}
\hline \multicolumn{10}{|c|}{$\begin{array}{r}\text { GASTOS INTERNOS Y PERSONAL EMPLEADO EN } \\
\text { POR COMUNIDADES AUTÓNOMAS Y SECTOF } \\
\text { Estructura porcentual }\end{array}$} \\
\hline \multirow{2}{*}{$\begin{array}{l}\text { Comunidades } \\
\text { Autónomas }\end{array}$} & \multicolumn{3}{|c|}{ Empresos e IPSFL } & \multicolumn{3}{|c|}{ Administración Püblica } & \multicolumn{3}{|c|}{ Enseñanza Superior } \\
\hline & Gostos internos & Personal en $1+D$ & Investigardores & Gastos internos & Personal en I+D & Investigadores & Gastos internos & Personal en I+D & Investigadores \\
\hline Andalucía & 6,1 & 7,2 & 6,1 & 14,4 & 14,0 & 13,9 & 16.1 & 14,3 & 13,3 \\
\hline Aragón & 2,3 & 3,0 & 2,6 & 2,6 & 3,0 & 3,1 & 1,8 & 3,3 & 4,1 \\
\hline Asturias & 1,3 & 1,4 & 1,3 & 1,5 & 1,5 & 1,3 & 2,2 & 1,9 & 2,0 \\
\hline Baleores & 0,2 & 0,3 & 0,3 & 1,0 & 1,2 & 1,5 & 1,1 & 0,9 & 1,0 \\
\hline Conarias & 1,0 & 0,9 & 0,7 & 3,4 & 3,7 & 3,8 & 3,7 & 4,0 & 3,9 \\
\hline Caniabria & 0,5 & 0,7 & 0,9 & 0,8 & 0,9 & 1,1 & 1,5 & 0,9 & 0,9 \\
\hline Castilla y león & 4,4 & 4,1 & 4,4 & 2.1 & 2,6 & 2,6 & 5,6 & 6,8 & 6.8 \\
\hline Costillo-ta Mancho & 1,2 & 1.1 & 0,9 & 1,1 & 0,9 & 1,0 & 1,8 & 1,5 & 1,4 \\
\hline Catoluña & 25.9 & 26,1 & 25,7 & 15,8 & 16,0 & 18,4 & 18,3 & 19,1 & 18,8 \\
\hline Com. Valenciana & 5,3 & 7,0 & 6,2 & 5,5 & 6,2 & 7,0 & 13,9 & 10,9 & 9,9 \\
\hline Extremoduro & 0,3 & 0,4 & 0,4 & 1,8 & 1.0 & 0,8 & 1,8 & 1,6 & 1,0 \\
\hline Galicia & 3,0 & 3,6 & 3,1 & 3,8 & 3,8 & 3,8 & 5,4 & 5,5 & 5,8 \\
\hline Madrid & 31,7 & 26,5 & 28,5 & 40,4 & 39,9 & 35,7 & 10,4 & 17,1 & 17,0 \\
\hline Murcia & 1,3 & 1,4 & 1,3 & 1,8 & 2,1 & 2,2 & 2,2 & 4,4 & 4,9 \\
\hline Navarro & 3,3 & 3,5 & 3,4 & 1,2 & 0,7 & 0,9 & 2,4 & 3,0 & 3,3 \\
\hline Pais Vasca & 11,4 & 12,1 & 13,6 & 2,0 & 1,9 & 2,5 & 5,1 & 4,2 & 4,7 \\
\hline Rioja & 0,8 & 0,7 & 0,5 & 0,7 & 0,4 & 0,3 & 0,3 & 0,4 & 0,5 \\
\hline Ceula y Melilla & 0,0 & 0,0 & 0,0 & 0,0 & 0,0 & 0,0 & 0,1 & 0,1 & 0,1 \\
\hline Total & 100,0 & 100,0 & 100,0 & 100,0 & 100,0 & 100,0 & 100,0 & 100,0 & 100,0 \\
\hline Fuente: iN & stica sobre c & dades de $1+D$. & 2006 & & 2 & & & & \\
\hline
\end{tabular}

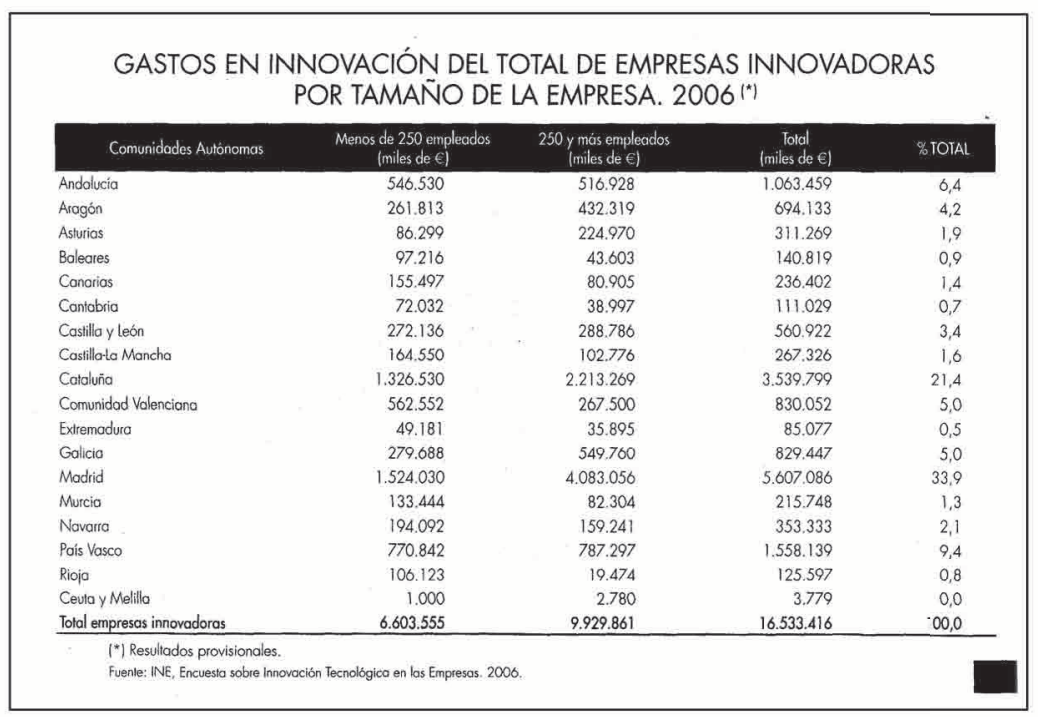




\begin{tabular}{|c|c|c|c|c|c|c|c|c|c|c|c|c|c|c|c|c|c|c|c|c|}
\hline \multirow{3}{*}{ Pais } & \multicolumn{20}{|c|}{$\begin{array}{c}\text { RECURSOS DESTINADOS A I+D EN LOS PAÍSES DE LA OCDE. } \\
1997-2006\end{array}$} \\
\hline & \multicolumn{10}{|c|}{ Gosto interno lofal an $1+\mathrm{D} \times 100 / \mathrm{FlB}$} & \multicolumn{10}{|c|}{ Persond 1+D (E]C) x 1000/poblacion activa } \\
\hline & 1997 & 1998 & 1999 & 2000 & 2001 & 2002 & 2003 & 2004 & 2005 & 2006 & 1997 & 1998 & 1999 & 2000 & 2001 & 2002 & 2003 & 2004 & 2005 & 2006 \\
\hline Alemonia & 2,24 & 2,27 & 2,40 & 2.45 & 2,46 & 2,49 & 2,52 & 2,49 & 2,48 & 2,51 & 11,6 & 11,5 & 12,1 & 12,3 & 12,1 & 12,1 & 12.0 & 11,8 & 11,7 & 11.7 \\
\hline Austalio & - & 1,47 & - & 1,51 & - & 1,69 & - & 1,78 & - & - & - & 9,8 & - & 9,9 & - & 10,8 & - & 11,5 & - & - \\
\hline Austia & 1.69 & 1.77 & 1.88 & 1.91 & 2.03 & 2,12 & 2.23 & 2.22 & 2,41 & 2,45 & - & 8,1 & - & - & - & 9.9 & - & 10.9 & 11,8 & 12,2 \\
\hline Bébica & 1,83 & 1.86 & 1,94 & 1,97 & 2,08 & 1,94 & 1,89 & 1,87 & 1,86 & 1,85 & 10,2 & 10,7 & 11,2 & 12,0 & 12,6 & 11,6 & 11,5 & 11,4 & 11,6 & 11,8 \\
\hline Canodo & 1,00 & 1,70 & 1,80 & 1,92 & 2,09 & 2,04 & 2,01 & 2,01 & 1,98 & 1,97 & 9,0 & 9,0 & 9,8 & 10,0 & 11,1 & 11,0 & 11,1 & 11,6 & - & - \\
\hline Corea & 2,48 & 2,34 & 2,25 & 2,39 & 2,59 & 2,53 & 2,63 & 2,85 & 2,98 & - & 0,3 & 0,0 & 6,4 & 0,2 & 7,4 & 7,5 & 8,1 & 8,3 & 9,1 & - \\
\hline Dinomarca & 1,92 & 2,04 & 2,18 & - & 2,39 & 2,51 & 2,58 & 2,50 & 2,45 & 2,43 & 12,0 & 12,4 & 127 & 13,2 & 13,9 & 14.9 & 14,0 & 14,8 & 15,1 & 15,6 \\
\hline Eslovenio & 1.31 & 1.37 & 1.41 & 1.43 & 1.55 & 1.52 & 1,32 & 1.45 & 1.49 & - & 8.4 & 8.6 & 8.9 & 8.9 & 8.8 & 8.9 & 7.1 & 7.1 & 8,9 & - \\
\hline Espoña & 0,80 & 0,87 & 0,86 & 0,91 & 0,91 & 0,99 & 1,05 & 1,06 & 1,12 & 1,20 & 5,1 & 5,7 & 5,8 & 6,7 & 7,0 & 7,2 & 7,8 & 8,0 & 8,4 & - \\
\hline Estados Unidos & 2,58 & 2,62 & 2,60 & 2,74 & 2,76 & 2,60 & 2,60 & 2,59 & 2,62 & 2,02 & - & - & - & - & - & - & - & - & - & - \\
\hline Finlondio & 2,70 & 2,86 & 3,16 & 3,34 & 3,30 & 3,36 & 3,43 & 3,45 & 3,48 & 3,45 & 16,5 & 18,4 & 19,6 & 20,2 & 20,3 & 20,9 & 21,8 & 22,3 & 21,8 & 21,8 \\
\hline Francio & 2,19 & 2,14 & 2,16 & 2,15 & 2,20 & 2,23 & 2,17 & 2,15 & 2,13 & 2,12 & 11,9 & 11,9 & 12,0 & 12,3 & 12,4 & 12,7 & 12,7 & 12,9 & 13,0 & - \\
\hline Grecio & 0.39 & - & 0.52 & - & 0.51 & - & 0.50 & 0.48 & 0.51 & 0.50 & 47 & - & 5.8 & - & 0.6 & - & 6,7 & - & 7,0 & 7,2 \\
\hline Hengrio & 0,70 & 0,60 & 0,67 & 0,78 & 0,92 & 1,00 & 0,93 & 0,88 & 0,94 & 1,00 & 5,2 & 5,1 & 5,2 & 5,7 & 5,6 & 5,8 & 5,0 & 5,5 & 5,5 & 6.1 \\
\hline Hando & 1.27 & 1.23 & 1.18 & 1,12 & 1,10 & 1,10 & 1,18 & 1.25 & 1.26 & 1,32 & 7.0 & 7.2 & 7.1 & 7,3 & 7.5 & 7,4 & 7.8 & 8,2 & 8,3 & 8,4 \\
\hline Bsondia & 1,83 & 2,01 & 2,30 & 2,68 & 2,96 & 2,97 & 2,82 & - & 2,78 & - & 14,6 & 14,9 & 15,3 & - & 17,8 & 17,3 & 18,1 & - & 19.5 & - \\
\hline balio & 1,03 & 1,05 & 1,02 & 1,05 & 1,09 & 1,13 & 1,11 & 1,10 & 1,10 & - & - & 6,3 & 6,1 & 6,3 & 6,4 & 6.8 & 6,7 & 6,7 & 7,2 & - \\
\hline
\end{tabular}

\begin{tabular}{|c|c|c|c|c|c|c|c|c|c|c|c|c|c|c|c|c|c|c|c|c|}
\hline \multicolumn{21}{|c|}{$\begin{array}{c}\text { RECURSOS DESTINADOS A I+D EN LOS PAÍSES DE LA OCDE (Continuación). } \\
1997-2006\end{array}$} \\
\hline \multirow{2}{*}{ Pais } & \multicolumn{10}{|c|}{ Gasto interno total en $1+D \times 100 / P i B$} & \multicolumn{10}{|c|}{ Personal $1+D(E J C) \times 1000 /$ población acliva } \\
\hline & 1997 & 1998 & 1999 & 2000 & 2001 & 2002 & 2003 & 2004 & 2005 & 2006 & 1997 & 1998 & 1999 & 2000 & 2001 & 2002 & 2003 & 2004 & 2005 & 2006 \\
\hline Jopón & 2,87 & 3,00 & 3,02 & 3,04 & 3,12 & 3,17 & 3,20 & 3.17 & 3,33 & - & 13,2 & 13,6 & 13,6 & 13,3 & 13,2 & 12.8 & 13,2 & 13,5 & 13,9 & - \\
\hline luxemburgo & - & - & - & 1,05 & - & - & 1,06 & 1,08 & 1,61 & - & - & - & - & 13,6 & - & - & 13,4 & 14,1 & 13,9 & - \\
\hline México & 0,34 & 0,38 & 0,43 & 0,37 & 0,39 & 0,44 & 0,43 & 0,47 & 0,50 & - & 1,0 & 1,0 & 1,1 & - & 1,1 & - & 1,5 & 1,9 & 2,1 & - \\
\hline Nonega & 1.63 & - & 1.64 & - & 1.59 & 1.66 & 1.71 & 1,59 & 1,52 & 1,49 & 10.9 & - & 10,9 & - & 11,5 & 11,5 & 12.2 & 12,5 & 12,7 & 13,0 \\
\hline Nuevo Zelando & 1,09 & - & 1,00 & - & 1,14 & - & 1,19 & - & 1,17 & - & 6,8 & - & 6,8 & - & 9,0 & - & 10,5 & - & 10,7 & - \\
\hline Paises Bajos & 1,99 & 1,90 & 1,96 & 1,82 & 1,80 & 1,72 & 1,70 & 1.78 & 1,73 & - & 10,9 & 11,0 & 10,9 & 10,9 & 10,9 & 10,0 & 10,4 & 11,0 & 10,7 & - \\
\hline Polonic & 0,05 & 0,67 & 0,69 & 0,64 & 0,02 & 0,56 & 0,54 & 0,56 & 0.57 & 0.56 . & 4,9 & 4,9 & 4.8 & 4,5 & 4,4 & 4,4 & 4,5 & 4.6 & 4,5 & 4,3 \\
\hline Pariugol & 0,59 & 0,05 & 0,71 & 0,76 & 0,80 & 0,76 & 0,74 & 0,77 & 0,81 & - & 3.7 & 3,8 & 40 & 4.2 & 4,3 & 4.5 & 4.7 & 4,7 & 4,6 & - \\
\hline Reino Unido & 1.81 & 1.80 & 1,87 & 1,86 & 1,83 & 1,83 & 1,79 & 1,73 & 1,78 & - & 9.4 & 10.1 & 10,5 & 10.4 & 10.8 & 11,1 & 10.9 & 10.8 & 10,9 & - \\
\hline $\begin{array}{l}\text { Repüblica } \\
\text { Checo }\end{array}$ & 1,08 & 1.15 & 1,14 & 1.21 & 1.20 & 1,20 & 1.25 & 1,25 & 1,41 & 1,54 & 4,5 & 4,4 & 4,6 & 4,7 & 5,1 & 5,0 & 5.5 & 5.0 & 8,4 & 9,2 \\
\hline $\begin{array}{l}\text { República } \\
\text { Essowoco }\end{array}$ & 1,07 & 0,78 & 0,05 & 0.65 & 0,63 & 0,57 & 0,58 & 0,51 & 0,51 & 0,49 & 0,5 & 6,5 & 5,8 & 5,8 & 5,4 & 5,2 & 5,1 & 5,4 & 5,4 & 57 \\
\hline Runnerio & 0,58 & 0,49 & 0.40 & 0,37 & 0,39 & 0,38 & 0,39 & 0,39 & 0,41 & 0,46 & 4.7 & 4,6 & 3,9 & 3,0 & 2.9 & 3.1 & 3,4 & 3.4 & 3,4 & 3,1 \\
\hline Suecia & 3,51 & & 3.62 & - & 4.25 & - & 3,95 & 3.77 & 3,89 & 3.82 & 15,0 & $=$ & 15,2 & - & 16.2 & - & 16,2 & 18,1 & 16,8 & 16.9 \\
\hline Suizo & - & - & - & 2,53 & - & - & - & 2,90 & - & - & - & - & - & 12.5 & - & - & - & 12,0 & - & - \\
\hline Turquía & 0,49 & 0,50 & 0,63 & 0,04 & 0,72 & 0,66 & 0,01 & 0,67 & 0,79 & - & 1,0 & 1,0 & 1.0 & 1,2 & 1,2 & 1,2 & 1,0 & 1,0 & 2.0 & - \\
\hline Toral $\propto C D E$ & 2,12 & 2,15 & 2,18 & 2,22 & 2,27 & 2,23 & 2,24 & 2,21 & 2,25 & - & - & - & - & - & - & - & - & - & - & - \\
\hline
\end{tabular}




\begin{tabular}{|c|c|c|c|c|c|c|c|c|c|c|c|c|c|c|c|c|c|c|c|c|c|}
\hline \multicolumn{22}{|c|}{$\begin{array}{r}\text { GASTO EN I+D EN LOS PAÍSES DE LA UE POR SECT } \\
\text { En porcentaje del PIB }\end{array}$} \\
\hline \multirow{2}{*}{ Poises } & \multicolumn{7}{|c|}{ Enpressis $\times 100 /$ FB } & \multicolumn{7}{|c|}{ 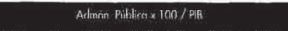 } & \multicolumn{7}{|c|}{ 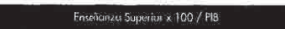 } \\
\hline & 2000 & 2001 & 2002 & 2003 & 2004 & 20025 & 2006 & 2000 & 2001 & 2002 & 2003 & 2004 & 2005 & 2006 & 2000 & 2001 & 2002 & 2003 & 2004 & 2005 & 2006 \\
\hline Alemona & $i, 73$ & 1,72 & 1,72 & 1.76 & 1,73 & 1,72 & 1,75 & 0,33 & 0,34 & 0,34 & 0.34 & 0,34 & 0,35 & 0,35 & 0,39 & 0,40 & 0,42 & 0,43 & 0,41 & 0,41 & 0,41 \\
\hline Austio & - & - & 1,42 & - & $1,51^{*}$ & 1,64 & 1,06 & - & - & 0,12 & - & 0,11 & 0,12 & 0,13 & - & - & 0,57 & - & 0,59 & 0,04 & 0,65 \\
\hline Belgico & 1,43 & 1,51 & 1,37 & 1,31 & 1,29 & 1.26 & 1,25 & 0,12 & 0.13 & 0.14 & 0,13 & 0,14 & 0,16 & 0.16 & 0,40 & 0.41 & 0,41 & 0,42 & 0,41 & 0.41 & 0,41 \\
\hline Dinamaco & - & 1,64 & 1,73 & 1,78 & 1.70 & 1,67 & 1,62 & 0,28 & 0,28 & 0,18 & 0,18 & 0,17 & 0,16 & 0,16 & 0.45 & 0,45 & 0,58 & 0,00 & 0.01 & 0,80 & 0,69 \\
\hline Estorenic & 0,80 & 0.90 & 0,91 & 0,84 & 0,97 & 0,88 & - & 0,37 & 0,38 & 0,35 & 0,29 & 0.20 & 0,36 & - & 0.24 & 0,25 & 0,24 & 0,18 & 0,10 & 0,25 & - \\
\hline Espoia & 0,49 & 0,48 & 0,54 & 0,57 & 0,58 & 0,00 & - & 0,14 & 0,15 & 0,15 & 0,16 & 0,17 & 0,19 & - & 0,27 & 0,28 & 0,29 & 0.32 & 0,31 & 0,33 & - \\
\hline Finabstia & 2,37 & 2.35 & 2.34 & 2,42 & 2,42 & 2,47 & 2,46 & 0.35 & 0.34 & 0.25 & 0,23 & 0.33 & 0.99 & 0,32 & 0,60 & 0.60 & 0.64 & 0.06 & 0.68 & 0.86 & 0.65 \\
\hline frascis & 1,34 & 1,39 & $\mid, 4 !$ & 1,30 & 1,30 & 1,34 & 1,34 & 0,37 & 0,36 & 0,37 & 0,36 & 0,37 & 0,37 & 0,37 & 0,40 & 0,42 & 0,42 & 0,42 & 0,40 & 0,40 & 0,38 \\
\hline Gecia & 0,13 & 0.17 & 0,16 & 0,16 & 0,15 & 0,16 & 0,15 & - & 0,11 & - & 0,10 & 0,10 & 0.10 & 0,10 & - & 0,23 & - & 0,23 & 0,23 & 0,28 & 0,24 \\
\hline Hoanda & 1,07 & 1,05 & 0,98 & 1,01 & 1,03 & 1.01 & 0,48 & 0.23 & 0,25 & 0,24 & 0,25 & 0.26 & 0.24 & - & 0,51 & 0.49 & 0.50 & 0,49 & - & - & - \\
\hline Hhuggio & 0,35 & 0,37 & 0,35 & 0,34 & 0,36 & 0,41 & 0.89 & 0,20 & 0.24 & 0,39 & 0,29 & 0,20 & 0,20 & - & 0.19 & 0,24 & 0.25 & 0,25 & 0.22 & 0.24 & 0.24 \\
\hline Hondo & 0.81 & 0,77 & 0,76 & 0,80 & 0,82 & 0,83 & 0,0 & 0,09 & 0,09 & 0,10 & 0,09 & 0,09 & 0,09 & 0,08 & 0,23 & 0,24 & 0,25 & 0,29 & 0,33 & 0,34 & 0,34 \\
\hline Holis & 0,52 & 0,53 & 0,54 & 0,52 & 0,52 & 0,55 & 0.54 & 0,20 & 0,20 & 0.20 & 0,19 & 0.20 & 0,19 & 0.19 & 0,32 & 0,35 & 0,37 & 0,37 & 0,36 & 0,33 & 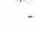 \\
\hline lixembargo & 1,53 & - & - & I.AB & $1, \not 6$ & 1,39 & - & 0,12 & 0,14 & 0,16 & 0,18 & 0,18 & 0,19 & 0,19 & 0,00 & 0,01 & - & 0,01 & 0,02 & 0.02 & 0,04 \\
\hline Palonis & 0,23 & 0,22 & 0,11 & 0,15 & 0,16 & 0,18 & 0,18 & 0,21 & 0,19 & 0.25 & 0,22 & 0,22 & 0,21 & 0,21 & 0,20 & 0,20 & 0,19 & 0,17 & 0,18 & 0.18 & 0,17 \\
\hline Portigd & 0.21 & 0,26 & 0,25 & 0.24 & 0.28 & 0,31 & $\ldots$ & 0.18 & 0,17 & 0,14 & 0.12 & 0.12 & 0.12 & - & 0.28 & 0.29 & 0.29 & 0.28 & 0.29 & 0.29 & - \\
\hline Reino Uhide & 1,21 & 1,20 & 1,19 & 1,14 & 1,09 & 1,10 & - & 0,23 & 0.18 & 0,17 & 0,19 & 0,18 & 0,19 & - & 0,36 & 0,42 & 0,44 & 0,43 & 0,43 & 0,45 & - \\
\hline Repidicos Checos & 0.73 & 0,72 & 0,73 & 0,76 & 0,70 & 0,91 & 1.02 & 0,31 & 0,29 & 0,28 & 0,29 & 0,26 & 0,26 & 0,27 & 0,17 & 0,19 & 0,10 & 0,10 & 0,18 & 0,23 & 0,25 \\
\hline Reppititiow Elonvos & 0,43 & 0,43 & 0.37 & 0,32 & 0.25 & 0.25 & 0.21 & 0.16 & 0.15 & 0.15 & 0,18 & 0.16 & 0.15 & 0.16 & 0.00 & 0.06 & 0,05 & 0,08 & 0,10 & 0.10 & 0.12 \\
\hline Stecio & - & 3.28 & - & 2,93 & 2,73 & 2,88 & 2,86 & - & 0,12 & - & 0,14 & 0,12 & 0,18 & 0,17 & - & 0,84 & - & 0.87 & 0,85 & 0,81 & 0,78 \\
\hline UE-15 & 1,19 & 1,21 & 1,20 & 1,20 & 1,18 & 1,18 & - & 0,25 & 0,24 & 0,24 & 0,24 & 0,24 & 0,24 & - & 0,38 & 0,40 & 0,12 & 0,02 & 0,41 & 0,12 & - \\
\hline UE:-27 & 1,11 & 1,12 & 1,11 & 1,11 & 1,09 & 1,08 & 1,09 & 0,25 & 0,24 & 0,24 & 0,24 & 0,24 & 0,24 & - & 0,36 & 0,38 & 0,39 & 0,39 & 0,38 & 0,39 & - \\
\hline
\end{tabular}

\begin{tabular}{|c|c|c|c|c|c|c|c|c|c|c|c|c|}
\hline \multicolumn{13}{|c|}{$\begin{array}{c}\text { GASTO EN I+D EN LOS PAÍSES DE AMÉRICA LATINA Y EL CARIBE. 1994-2005 } \\
\text { En porcentaje del PIB }\end{array}$} \\
\hline Paises & 1994 & 1995 & 1996 & 1997 & I998 & 1999 & 2000 & 2001 & 2002 & 2003 & 2004 & 2005 \\
\hline A Agentina & - & - & 0,42 & 0,42 & 0,41 & 0,45 & 0.44 & 0,42 & 0,39 & 0,41 & 0,44 & 0.46 \\
\hline Bolivio & 0.40 & 0.36 & 0,33 & 0,32 & 0,29 & 0,29 & 0,28 & 0,27 & 0,26 & - & - & - \\
\hline Brosil & 0,92 & 0,87 & 0,72 & - & - & - & 0,94 & 0,96 & 0,91 & 0,88 & 0,83 & 0,82 \\
\hline Conodó & 1,73 & 1,70 & 1,65 & 1,66 & 1,76 & 1,80 & 1,91 & 2.09 & 2,04 & 2,01 & 2,01 & 1.98 \\
\hline Chile & 0,62 & 0,62 & 0,53 & 0,49 & 0,50 & 0,51 & 0,53 & 0,53 & 0,08 & 0.67 & 0,68 & - \\
\hline Colombia & - & 0,29 & 0,30 & 0,27 & 0,21 & 0,20 & 0,18 & 0.17 & - & - & - & - \\
\hline Costa Rico & - & - & 0,33 & 0,32 & 0,28 & 0,36 & 0,43 & - & - & 0,39 & 0,41 & - \\
\hline Cuba & 0.55 & 0,47 & 0,38 & 0,43 & 0,54 & 0,50 & 0,45 & 0,53 & 0,53 & 0,54 & 0,56 & 0,51 \\
\hline Ecuodor & - & 0.08 & 0,10 & 0,09 & 0,00 & - & - & 0.06 & 0.06 & 0,07 & - & - \\
\hline El Solvador & - & - & - & - & 0.08 & - & - & - & - & - & - & - \\
\hline Españo & 0.85 & 0.81 & 0,83 & 0,82 & 0,89 & 0,88 & 0,94 & 0.95 & 1,03 & 1,10 & 1,07 & 1,13 \\
\hline Estodas Unidos & 2,30 & 2,48 & 2,52 & 2,55 & 2,59 & 2,63 & 2,70 & 2,71 & 2,64 & 2,59 & 2,67 & $2, \infty 0$ \\
\hline Gualendo & - & - & - & - & 0.00 & 0,00 & 0.00 & 0,00 & 0,00 & 0,00 & 0.00 & 0,03 \\
\hline Honduros & - & - & - & - & - & - & 0,06 & 0,05 & 0.06 & 0.06 & - & - \\
\hline Jamoica & - & - & - & - & - & - & - & 0,06 & 0,07 & - & - & - \\
\hline Mbxico & 0,29 & 0.31 & 0.31 & 0.34 & 0.38 & 0.43 & 0,37 & 0,39 & 0,42 & 0,45 & 0,44 & 0,46 \\
\hline Nicarogua & - & - & - & 0,08 & - & - & - & - & 0,05 & - & - & - \\
\hline Ponomé & 0,37 & 0,38 & 0,38 & 0,37 & 0,34 & 0,35 & 0,40 & 0.40 & 0,36 & 0,34 & 0,24 & 0,25 \\
\hline Poraguay & - & - & - & - & - & - & - & 0,09 & 0,11 & 0,08 & 0,08 & 0,09 \\
\hline Perú & - & - & - & 0,08 & 0.10 & 0,10 & 0,11 & 0,11 & 0,10 & 0.10 & 0,16 & - \\
\hline Portugal & - & 0,54 & - & 0,59 & 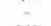 & 0.71 & - & 0,80 & - & 0,74 & - & 0,81 \\
\hline Trinidad y Tobago & - & - & 0,10 & 0.11 & 0.13 & 0.12 & 0.11 & 0,10 & 0,14 & 0,12 & 0.12 & 0,13 \\
\hline Unuguay & 0.14 & 0.28 & 0.28 & 0,42 & 0,23 & 0,26 & 0,24 & - & 0.26 & - & - & - \\
\hline Venezuelo"II & 0,58 & 0,61 & 0.45 & 0,43 & 0.39 & 0.39 & 0,38 & 0.49 & 0,40 & 0,29 & 0.25 & 0,23 \\
\hline América Lotina y el Caribe ${ }^{\text {pr. }}$ & 0,53 & 0,57 & 0,51 & 0,52 & 0,55 & 0,55 & 0,55 & 0,54 & 0,54 & 0,54 & 0,52 & 0,54 \\
\hline Iberoamerica & 0,61 & 0,63 & 0,59 & 0,59 & 0,63 & 0,64 & 0,64 & 0,65 & 0,68 & 0,73 & 0,71 & 0,73 \\
\hline Total 12 & 1,97 & 2,02 & 2,02 & 2,05 & 2,10 & 2,18 & 2,24 & 2,27 & 2,25 & 2,24 & 2,16 & 2,15 \\
\hline $\begin{array}{l}\text { (1) Se refier } \\
\text { (2) Dalos es } \\
\text { Fuerle. RiCY }\end{array}$ & $\begin{array}{l}\text { encia y } \\
\text { os. } \\
\text { xdo de k }\end{array}$ & ologia & general. & & 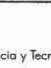 & & 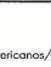 & 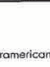 & & & $\because$ & \\
\hline
\end{tabular}

